\title{
Revision of charipine aphid hyperparasitoids (Hymenoptera: Cynipoidea: Figitidae) from central Europe
}

\author{
Mar Ferrer-Suay, Petr Starý, Jesús Selfa \& Juli Pujade-Villar
}

Ferrer-Suay, M., Starý, P., Selfa, J. \& Pujade-Villar, J. 2017: Revision of charipine aphid hyperparasitoids (Hymenoptera: Cynipoidea: Figitidae) from central Europe. — Entomol. Fennica 28: 113-147.

The Charipinae species of Central Europe are reviewed. Based on 1,439 specimens, 36 species were identified. A diagnosis for each species is provided and the diagnostic features illustrated. Alloxysta hendrickxi (Benoit, 1956) and Alloxysta pilosa Ferrer-Suay \& Pujade-Villar, 2013, are recorded from Europe for the first time. All the other species identified are recorded for the first time from central Europe, mostly from the Czech and Slovak Republics but also from Slovenia and Poland. New trophic relationships are described for some species, which considerably improves the knowledge of Charipinae hosts. In total 389 new trophic relations were established.

M. Ferrer-Suay \& J. Pujade-Villar, Universitat de Barcelona, Facultat de Biologia, Departament de Biologia Animal. Avda. Diagonal 645, 08028-Barcelona,Spain; E-mails:jpujade@ub.edu,mar.ferrer.suay@gmail.com P. Starý, Laboratory of Aphidology, Institute of Entomology, Biology Centre ASCR, Branisovska 31, 37005 Ceske Budejovice, Czech Republic; E-mail: stary@entu.cas.cz

J. Selfa, Universitat de Valčncia, Facultat de Cičncies Biològiques, Departament de Zoologia. Campus de Burjassot-Paterna, Dr. Moliner 50, 46100 Burjassot (Valčncia), Spain ; E-mail:jesus.selfa@uv.es

Received 4 December 2015, accepted 29 December 2016

\section{Introduction}

Charipinae is a subfamily composed of very small wasps $(0.8-2.0 \mathrm{~mm})$, with smooth and shiny bodies. This subfamily is economically very important because the species act as secondary parasitoids of aphids via Aphidiinae (Hymenoptera: Braconidae) and Aphelininae (Hymenoptera: Aphelinidae) and secondary parasitoids of psyllids via Encyrtidae (Hymenoptera: Chalcidoidea) (Menke \& Evenhuis 1991). Due to few morphological features, the taxonomy of Charipinae has been very complicated. However, re- cently all the described species have been revised (Ferrer-Suay et al. 2012b, c, 2013a, b, c, d), making species identification possible.

The basis of the present work is numerous samples collected all over the world, as a part of studies on Aphidiinae. However, the material was mainly collected in the Czech and Slovak Republics (former Czechoslovakia), reflecting the early phases of research undertaken by P. Starý. His approach was based on sampling and rearing tritrophic associations (plant-aphid-parasitoidshyperparasitoids), taken throughout these countries in different habitats and years. A number of 
other countries were also occasionaly sampled. Previously, only one study has been published on the Charipinae present in Europe (Balkan Peninsula), describing two new species and establishing many new records (Ferrer-Suay et al. 2013f). The only species previously cited from the Czech Republic is Alloxysta postica (Hartig, 1841) by Dalla Torre \& Kieffer (1910: 257).

In this study, 36 species have been identified, based on a total 1,439 specimens. For each of the species recognized, a diagnosis, list of material studied, host and distribution are provided. Most of the species here identified are recorded for the first time from central Europe (the Czech Republic, the Slovak Republic and some from Slovenia and Poland). Additionally, new trophic relationships are documented for the first time for some species, which considerably improves knowledge of Charipinae hosts. This information is very useful for the analysis of host specialization in this subfamily to augment the most recent publication (Ferrer-Suay et al. 2014).

The goal of this work is to improve the knowledge of Charipinae hosts. This paper presents important information on the natural history of some Charipinae species and is based on a relatively large dataset of reared parasitoids. These types of studies are the base of the ecological knowledge of the subfamily Charipinae, which will be very useful in the future for the biological control programs.

\section{Materials and methods}

The approach of the fieldwork was to determine tritrophic associations (plant-aphid-parasitoid) in different habitats. A piece of aphid-infested plant was gently cut with scissors and transferred into a plastic jar $(250-500 \mathrm{~cm})$ covered by nylon mesh. The plant was either identified in situ or taken as a herbarium sample. Also, part of the aphids, and even attending ants, was preserved in $70 \%$ ethanol for later identification. The jars were then transferred to the laboratory where they were kept at room temperature or in a temperature controlled room under $+18-24{ }^{\circ} \mathrm{C}$ and generally visited daily to sample emerging parasitoids. However, the samples were maintained for about two next weeks, when the whole sample was re- visited to collect the other (hyper) parasitoids and, eventually, other natural enemies from the litter on the bottom. Each sample was numbered.

The specimens were studied using a stereo microscope (NIKON SMZ-1) and environmental scanning electron microscope (FEI Quanta 200 ESEM) belonging to "Serveis Cientificotècnics de la Universiatat de Barcelona". The field-emission gun environmental scanning electron microscope was used for high-resolution imaging without gold-coating of the specimens.

The morphological terms used are taken from Paretas-Martínez et al. (2007). The measurements and abbreviations include F1-F12 for the first and subsequent flagellomeres. The width of the forewing radial cell is measured from the margin of the wing to the beginning Rs vein. The transfacial line is measured as the distance between the inner margins of the compound eyes, measured across the face through the antennal sockets divided by the height of the eye. The malar space is measured by the distance from the lower part of the gena from the mouthparts to the ventral margin of the compound eye, divided by the height of the eye. In the descriptions, females and males of each species have the same characters except where indicated.

The new host's records have an asterisk before the name in the Material studied section for each species and also in Table 1. Abbreviations used in the locality data (the Czech Republic and the Slovak Republic) in the Material studied sections are:

Boh, B. - Bohemia

Mor, M. - Moravia (parts of the Czech Republic)

Slov, S. - the Slovak Republic

bor. - borealis

c. - centralis

m. - meridionalis

occ. - occidentalis

or. - orientalis

$\mathrm{XX} / \mathrm{YY}$ - sample numbers (YY) in the individual years (XX). e.g. $58=1958,66=1966$

BZKU - Botanická zahrada KU, Praha 2 = Botanical garden of the Charles University

For better comparison, the figures of the antennae of Alloxysta species are grouped in Fig. 1 and those of Phaenoglyphis species in Fig. 2, the ra- 
Table 1. List of aphid-parasitoid host records for the Charipinae species identified from the Stary collection. The new host records have an asterisk before the name of each species. The specific relationships between aphids and primary parasitoids are presented in the material studied section of each species.

\begin{tabular}{|c|c|c|}
\hline Charipinae species & Aphid & Primary parasitoid \\
\hline Alloxysta arcuata & $\begin{array}{l}\text { Aphis sp. } \\
\text { Aphis brohmeri } \\
{ }^{*} \text { Aphis cichorii } \\
{ }^{*} \text { Aphis cognatella } \\
{ }^{*} \text { Aphis craccae } \\
{ }^{*} \text { Aphis craccivora } \\
\text { Aphis fabae } \\
{ }^{*} \text { Aphis farinosa } \\
\text { Aphis idaei } \\
{ }^{*} \text { Aphis intybi } \\
\text { Aphis nasturtii } \\
{ }^{*} \text { Aphis pomi } \\
{ }^{*} \text { Aphis salviae } \\
\text { Aphis urticata } \\
{ }^{*} \text { Aphis viburni } \\
\text { Brachycaudus sp. } \\
{ }^{*} \text { Brachycaudus cardui } \\
\text { Dysaphis plantaginea } \\
\text { Eucallipterus tiliae } \\
\text { Euceraphis punctipennis } \\
\text { *Hyadaphis foeniculi } \\
\text { Impatientinum balsamines } \\
{ }^{*} \text { Lipaphis erysimi } \\
\text { Macrosiphum rosae } \\
{ }^{*} \text { Microlophium carnosum } \\
\text { Myzaphis rosarum } \\
\text { Myzus cerasi } \\
\text { Myzus ligustri } \\
{ }^{*} \text { Rhopalosiphum insertum } \\
{ }^{*} \text { Rhopalosiphum nymphaeae } \\
\text { Schizaphistyphaeae }\end{array}$ & 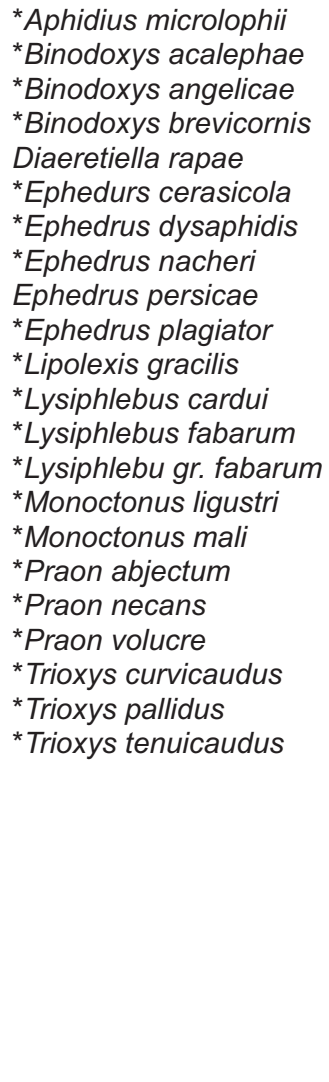 \\
\hline Alloxysta basimacula & ${ }^{*}$ Kallistaphis flava & \\
\hline Alloxysta brachyptera & $\begin{array}{l}\text { *Hayhurstia atriplicis } \\
\text { Hydaphias sp. }\end{array}$ & ${ }^{*}$ Diaretiella rapae \\
\hline Alloxysta brevis & $\begin{array}{l}\text { Aphis sp. } \\
{ }^{*} \text { Aphis brohmeri } \\
{ }^{*} \text { Aphis cichorii } \\
\text { *Aphis craccae } \\
\text { Aphis fabae } \\
{ }^{*} \text { Aphis farinosa } \\
{ }^{*} \text { Aphis idaei } \\
{ }^{*} \text { Aphis intybi } \\
{ }^{*} \text { Aphis jacobaeae } \\
{ }^{*} \text { Aphis nasturtii } \\
{ }^{*} \text { Aphis pomi } \\
\text { Aphis rumicis } \\
\text { *Aphis sambuci } \\
\text { *Aphis spiraephaga } \\
\text { *Aphis urticata } \\
\text { *Aphis viburni } \\
\text { Brachycaudus sp. } \\
\text { Cinara sp. } \\
\text { Cryptosiphum artemisiae }\end{array}$ & $\begin{array}{l}{ }^{*} \text { Aphidius absinthii } \\
{ }^{*} \text { Aphidius arvensis } \\
{ }^{*} \text { Aphidius colemani } \\
{ }^{*} \text { Aphidius matricariae } \\
\text { Aphidius galiobii } \\
{ }^{*} \text { Binodoxys acalephae } \\
\text { *Binodoxys angelicae } \\
\text { *Binodoxys brevicornis } \\
\text { Diaretiella rapae } \\
{ }^{*} \text { Ephedrus nacheri } \\
\text { Ephedrus persicae } \\
{ }^{*} \text { Ephedrus plagiator } \\
\text { *Lipolexis gracilis } \\
{ }^{*} \text { Lysiphlebus cardui } \\
{ }^{*} \text { Lysiphlebus fabarum } \\
{ }^{*} \text { Praon abjectum } \\
\text { *Praon necans } \\
\text { Praon volucre }\end{array}$ \\
\hline
\end{tabular}


Table 1, continued

Alloxysta castanea

Alloxysta circumscripta

Alloxysta citripes

Alloxysta consobrina

Alloxysta fracticornis Alloxysta halterata Alloxysta hendrikxi
Galiobium

${ }^{*}$ Hayhurstia atriplicis

${ }^{*}$ Hyadaphis foeniculi

*Macrosiphum rosae

${ }^{*}$ Myzus ligustri

${ }^{*}$ Rhopalosiphum nymphaeae

Aphis sp.

${ }^{*}$ Aphis fabae

Aulacorthum sp.

Betulaphis sp.

Cavariella sp.

${ }^{*}$ Ceruraphis eriophori

Cryptomyzus sp.

Euceraphis sp.

Hyalopterus pruni

Hyperomyzus sp.

*Liosomaphis berberidis

* Macrosiphum euphorbiellus

Macrosiphum prenanthidis

*Macrosiphum rosae

Myzaphis rosarum

Ovatus sp.

*Phorodon humili

${ }^{*}$ Rhopalosiphoninus sp.

${ }^{*}$ Rhopalosiphum padi

Sitobion sp.

${ }^{*}$ Aphis fabae

${ }^{*}$ Aphis cognatella

*Brachycaudus cardui

Chromaphis juglandicola

* Drepanosiphum platanoides

Eucallipterus tiliae

Hoplocallis ruperti

*Myzocallis carpini

Myzocallis coryli

Periphyllus sp.

Thelaxes sp.

Tinocallis sp.

Tuberculatus annulatus

${ }^{*}$ Acyrthosiphon pisum

Aphis fabae

*Aphis urticata

Brevicoryne brassicae

Cavariella sp.

${ }^{*}$ Coloradoa achilleae

Cryptomyzus ribis

Hyadaphis sp.

* Liosomaphis berberidis

Nasonovia sp.

*Therioaphis trifolii

*Acyrthosiphon sp.

*Aulacorthum langei

*Aphis fabae

Aphis poterii
${ }^{*}$ Aphidius aquilus

Aphidius rosae

${ }^{*}$ Aphidius salicis

${ }^{*}$ Aphidius transcaspicus

*Aphidius urticae

${ }^{*}$ Aphidius uzbekistanicus

Binodoxys angelicae

*Ephedrus lacertosus

*Ephedrus laevicollis

*Ephedrus plagiator

* Lysiphlebus cardui.

Praon volucre

\author{
${ }^{*}$ Binodoxys angelicae \\ *Praon abjectum \\ *Binodoxys angelicae \\ Falciconus pseudoplatani \\ *Lysiphlebus gr. fabarum \\ *Praon flavinode \\ *Trioxys cirsii \\ *Trioxys curvicaudus \\ Trioxys pallidus \\ *Trioxys tenuicaudus
}

Aphidius sp.

*Aphidius arvensis

*Aphidius ervi

*Aphidius hieraciorum

${ }^{*}$ Aphidius hortensis

*Aphidius ribis

Aphidius salicis

${ }^{*}$ Binodoxys angelicae

*Binodoxys brevicornis

Diaretiella rapae

* Lysiphlebus fabarum

* Lysiphlebus gr. fabarum

*Praon exsoletum

${ }^{*}$ Aphidius urticae 
Table 1, continued

Alloxysta kovilovika

Alloxysta leunisii

Alloxysta macrophadna

Alloxysta melanogaster

Alloxysta mullensis

Alloxysta nigricans

Alloxysta obscurata

Alloxysta pallidicornis

Alloxysta pilipennis

Alloxysta pilosa

Alloxysta pleuralis
*Brachycaudus helichrysi

*Brevicoryne brassicae

Acyrthosiphon pisum

Amphorophora ampullata

Dysaphis sp.

Euceraphis sp.

Judenkoa sp.

*Macrosiphum daphnidis

*Macrosiphum funestum

*Macrosiphum gei

* Macrosiphum rosae

Rhopalomyzus sp.

*Uroleucon aeneus

*Amphorophora sp.

*Myzus cerasi

Rhopalosiphoninus sp.

Aphis sp.

${ }^{*}$ Aphis craccivora

Aphis fabae

${ }^{*}$ Aphis farinosa

${ }^{*}$ Aphis frangulae

Aphis jacobaeae

${ }^{*}$ Aphis pomi

${ }^{*}$ Aphis sambuci

*Aphis viburni

Sipha sp.

Periphyllus sp.

Aulacorthum sp.

Linosiphon sp.

*Myzus galeopsidis

Cinara sp.

Acyrthosiphon caraganae

Aphis fabae

${ }^{*}$ Aphis pomi

*Cryptomyzus ribis

*Drepanosiphum platanoides

Dysaphis sp.

Dysaphis plantaginea

Eucallipterus sp.

*Macrosiphum rosae

Macrosiphoniella oblonga

Myzus cerasi

Myzus varians

Periphyllus sp.

Periphyllus aceris

Periphyllus hirticonis

${ }^{*}$ Peryphyllus lyropictus

Peryphyllus rthenanus

* Peryphyllus testudinaceus

*Phorodon humili

Rhopalomyzus sp.

*Impatientinum balsamines

Aphis sp.

*Aphis cognatella

Aphis craccae
*Diaretiella rapae

Aphidius ervi

*Aphidius rosae

*Aphidius urticae

${ }^{*}$ Ephedrus persicae

*Ephedrus plagiator

*Praon volucre

*Ephedrus cerasicola

${ }^{*}$ Ephedrus lacertosus

Ephedrus persicae

${ }^{*}$ Ephedrus plagiator

*Adialytus ambiguus

*Binodoxys angelicae

*Ephedrus plagiator

*Lipolexis gracilis

*Lysiphlebus cardui

Lysiphlebus fabarum

Praon abjectum

${ }^{*}$ Euaphidius setiger

*Aphidius urticae

${ }^{*}$ Aphidius ribis

*Pauesia laricis

*Pauesia pini

*Aphidius phalangomyzi

${ }^{*}$ Areopraon silvestre

Binodoxys angelicae

*Dyscritulus planiceps

*Ephedrus cerasicola

*Ephedrus dysaphidis

*Ephedrus persicae

*Ephedrus plagiator

${ }^{*}$ Euaphidius setiger

${ }^{*}$ Falciconus pseudoplatani

* Lysiphlebus fabarum

*Praon volucre

*Trioxys cirsii

*Trioxys curvicaudus

Trioxys falcatus
*Monoctonus nervosus
*Aphidius salicis
*Binodoxys acalephae
*Binodoxys angelicae


Alloxysta postica

Alloxysta pusilla

Alloxysta ramulifera

Alloxysta sawoniewiczi

Alloxysta semiaperta

Alloxysta victrix
Aphis craccivora

Aphis fabae

${ }^{*}$ Aphis farinosa

*Aphis intybi

${ }^{*}$ Aphis mordwilkiana

${ }^{*}$ Apis nasturtii

Aphis pomi

*Aphis salviae

*Aphis spiraephaga

${ }^{*}$ Aphis urticata

${ }^{*}$ Aphis viburni

${ }^{*}$ Cavariella sp.

*Myzus cerasi

Brachycaudus

Cavariella sp.

Aphis sp.

${ }^{*}$ Aphis euphorbiae

Aphis fabae

${ }^{*}$ Aphis farinosa

${ }^{*}$ Aphis intybi

${ }^{*}$ Aphis polygonata

${ }^{*}$ Aphis salviae

*Aphis urticata

Capitophorus

Cavariella sp.

Hyalopterus pruni

${ }^{*}$ Myzus ligustri

*Phorodon humuli

${ }^{*}$ Rhopalomyzus alpigenae

Schizaphistyphaeae

Aphis sp.

*Aphis fabae

Aphis rumicis

${ }^{*}$ Aphis spiraephaga

${ }^{*}$ Aphis urticata

*Lipaphis erysimi

*Aphis farinosa

Hyadaphis foeniculi

Hyperomyzus sp.

*Impatientinum asiaticum

*Impatientinum balsamines

Linosiphon sp.

*Macrosiphum gei

*Macrosiphum rosae

Myzocallis sp.

Acyrthosiphon sp.

${ }^{*}$ Acyrthosiphum caraganae

*Amphorophora ampullata

${ }^{*}$ Aphis cognatella

Aulacorthum sp.

Betulaphis sp.

Brachycaudus sp.

*Brachycaudus klugkisti

Brevicoryne brassicae

Capitophorus sp.
*Ephedrus cerasicola

*Ephedrus helleni

${ }^{*}$ Ephedrus nacheri

${ }^{*}$ Ephedrus persicae

*Lipolexis gracilis

* Lysiphlebus cardui

Lysiphlebus fabarum

*Lysiphlebus fritzmuelleri

*Praon abjectum

*Aphidius salicis

Binodoxys angelicae

*Ephedrus persicae

*Aphidius matricariae

*Binodoxys acalephae

*Binodoxys angelicae

*Diaeretiella rapae

*Ephedrus plagiator

* Lipolexis gracilis

* Lysiphlebus fabarum

*Monoctonus ligustri

*Praon abjectum

*Praon volucre

*Binodoxys angelicae

*Ephedrus nacheri

* Lysiphlebus fabarum

* Lysiphlebus confusus

*Praon volucre

*Binodoxys angelicae

*Aphidius rosae

*Aphidius urticae

* Ephedrus plagiator

*Praon longicorne

*Praon volucre

${ }^{*}$ Aphidius aquilus

${ }^{*}$ Aphidius arvensis

Aphidius ervi

*Aphidius hieraciorum

*Aphidius linosiphonis

Aphidius matricariae

${ }^{*}$ Aphidius microlophii

*Aphidius ribis

Aphidius rosae

Aphidius salicis 
Phaenoglyphis evenhuisi

Phaenoglyphis heterocera

Phaenoglyphis longicornis Phaenoglyphis ruficornis Phaenoglyphis salicis

Phaenoglyphis stricta Phaenoglyphis villosa

Myzus persicae

Phaenoglyphis xanthochroa
Cavariella sp.

Coloradoa artemisiae

${ }^{*}$ Cryptomyzus ribis

Macrosiphum sp.

*Macrosiphum euphorbiae

*Macrosiphum funestum

*Macrosiphum gei

*Macrosiphum melampyri

* Macrosiphum oredonensis

*Macrosiphum prenathidis

Macrosiphum rosae

Microlophium carnosum

*Myzus ajugae

Myzus galeopsidis

Myzus persicae

Nasonovia sp.

Peryphyllus sp.

*Periphyllus lyropictus

Rhopalosiphum nymphaeae

${ }^{*}$ Rhopalosiphum padi

Sitobion avenae

Brachycaudus lychnidis

Aphis fabae

${ }^{*}$ Aphis sambuci

Brachycaudus sp.

*Uroleucon cichorii

Uroleucon sp.

Cinara juniperi

*Aphis fabae

Cavariella sp.

${ }^{*}$ Aphis urticata

${ }^{*}$ Aphis craccae

Aphis fabae

Aphis farinosa

Aphis spiraephaga

${ }^{*}$ Aphis urticata

Brevicoryne brassicae

Hyadaphis sp.

Hyalopterus pruni

Hyperomyzus sp.

Liosomaphis berberidis

Myzus cerasi

Myzus ligustri

*Monoctonus ligustri

*Rhopalosiphum nymphaeae

Schizaphis sp.

Praon volucre

*Impatientinum balsamines
*Aphidius urticae

Aphidius uzbekistanicus

*Areopraon silvestris

${ }^{*}$ Betuloxys compressicornis

*Binodoxys angelicae

*Diaretiella rapae

*Ephedrus lacertosus

${ }^{*}$ Ephedrus plagiator

${ }^{*}$ Euaphidius setiger

Lysiphlebus fabarum

*Praon pubescens

*Praon necans

Praon volucre

*Praon yomenae

*Toxares deltiger

*Diaretiella rapae

*Praon volucre

*Binodoxys angelicae

*Lipolexis gracilis

* Lysiphlebus fabarum

*Lysiphlebus gr. fabarum

*Praon abjectum

${ }^{*}$ Aphidius funebris

*Pauesia juniperorum

*Lysiphlebus fabarum

*Aphidius salicis

*Binodoxys brevicornis

*Binodoxys acalephae

Aphidius hortensis

${ }^{*}$ Aphidius matricariae

*Aphidius transcaspicus

*Aphidius urticae

*Binodoxys angelicae

*Binodoxys acalephae

Diaretiella rapae

Ephedrus persicae

Ephedrus plagiator

*Lysiphlebus cardui

Lysiphlebus fabarum

*Lysiphlebus fritzmuelleri

*Praon abjectum

*Praon necans

*Monoctonus nervosus 
dial cells of Alloxysta species in Figs 3 and 4, different types of pronotum in Fig. 5 and different types of propodeum in Fig. 6.

The material is deposited in P. Starý's personal collection (when not indicated) or in the University of Barcelona (UB) (indicated).

\section{Annotated list of Charipinae aphid hyperparasitoids from the Czech and Slovak Republics}

\subsection{Alloxysta arcuata (Kieffer, 1902)}

Diagnosis. Alloxysta arcuata is mainly characterized having a small closed radial cell 2.3 times as long as wide (Fig. 3a), pronotal carinae present (Fig. 5a), propodeal carinae forming a plate (Fig. 6a), female antennae with beginning of rhinaria in F3; F1 subequal to pedicel and longer to F2, F2 subequal to F3 (Fig. 1a), male antennae with beginning of rhinaria in F2, F2 slightly curved, F1 longer than pedicel, F1 subequal to F2, F2 shorter than F3. It is similar to Alloxysta ramulifera (Thomson, 1862) but can be differentiated by the beginning of rhinaria: in F3 in A. arcuata (Fig. 1a) while in F4 in $A$. ramulifera (Fig. 1y); shape of pronotal carinae: well defined and visible in $A$. arcuata but small and sometimes difficult to see under the pubescence in A. ramulifera; size of radial cell: 2.3 times as long as wide in A. arcuata (Fig. $3 a$ ) but 2.0 in $A$. ramulifera (Fig. 4i) and shape of propodeal carinae: with curved sides in $A$. arcuata and with straight sides in $A$. ramulifera.

Material studied. 62 \& 909. "57/96, Praha, BZKU, B. c., 3.VI.1957, Aphis fabae, Euonymus europaeus": 29; "58/120, Praha, Seminářská zahrada, B. c., 8.VI.1958, Aphis fabae, Philadelphus": 1ð̄; "58/228, Komárov, B. or. 23.VII.1958, *Aphis cognatella, Euonymus europaeus, *Binodoxys angelicae": 1 +; " $58 / 229$, Praha, BZKU, B. c., 28.71958, Aphis fabae, Chenopodium album, *Lysiphlebus fabarum": $1 \widehat{\jmath} \& 2$ \% ; "58/231, Praha, BZKU, B. c., 28.VII.1958, *Aphis craccivora, Robinia pseudoacacia, *Ephedrus plagiator": 10; "58/29, Š́d, Fil'ákovo, Slov. m., 22.V.1958, Aphis fabae, Euonymus europaeus": 1 ; ; "58/61, Pusté Čemerné, nr. Michalovice, Slov. or.,
26.V.1958, Aphis fabae, Euonymus europaeus": $2 \widehat{\jmath}$ \& 1q; “58/84, Chocholná, Trenčín, Slov. occ., 29.V.1958, Myzus ligustri, Ligustrum, *Ephedrus cerasicola": 1ठ̄ં; "59/111, Praha, BZKU, B.c., 9.VI.1959, *Aphis viburni, Viburnum opulus, Binodoxys angelicae": 10 \& 3 \% ; "59/20, Kysak, Slov. or., 23.V.1959, Aphis fabae, Euonymus europaeus, Ephedrus plagiator": 1ठ;; "59/217, Zátaví, B.m., 26.VI.1959, Myzaphis, Rosa": 3; "59/232, Orlík, B. m., 26.VI.1959, Aphis, Cirsium, Binodoxys angelicae": 1; "59/79, Praha, Seminářská zahrada, B.c., 24.V.1959, Aphis fabae, Euonymus europaeus, Binodoxys angelicae": 1; "60/116, Čelákovice B. c., 26.V.1960, Dysaphis, Crataegus": 1q; "60/141, Král.Chlmec, Slov. or., 1.VI.1960, Aphis urticata, Urtica dioica, *Binodoxys acalephae": 1 đิ \& 1q; "60/164, Král.Chlmec, Slov. or., 1.VI.1960, Aphis, Onobrychis sativa, Binodoxys acalephae": 19; "60/2, Malá Jiz. Louka, Jizerské hory, B.bor., 19.V.1960, Cinara sp., Pinus uncinnata": $6{ }^{\lambda} \& 3 \bigcirc$; “60/212, Uherčice, M. m., 4.VI.1960, *Aphis salviae, Salvia nemorosa, Binodoxys acalephae, *Lipolexis gracilis": 1 \%; "60/320, Praha, Seminářská zahrada, B.c., 12.VI.1960, Aphis urticata, Urtica dioica, Binodoxys acalephae": 1О̄; "60/337, Praha, BZKU, B. c.,15.VI.1960, Myzus cerasi, Prunus cerasus, Ephedrus persicae": 2ᄋ; "60/380, Dobříš, B. c., 23.VI.1960, M. only, Quercus": 2ᄋ; "60/388, Praha, BZKU, B. c., 24.VI.1960, Dysaphis, Pyrus communis": 1ð̄; “60/411, Praha, Vojanovy sady, B. c., 26.VI.1960, Eucallipterus tiliae, Tilia, *Trioxys pallidus, *Trioxys curvicaudus": 19; "60/417, Praha, Chotkovy sady, B.c., 27.VI.1960, Eucallipterus, Tilia, *Trioxys tenuicaudus": 19; "60/42, Pouzdřany, M. m., 19.V.1960, Myzus cerasi, Prunus avium, *Lipolexis gracilis": 1 q; “60/424, Praha, BZKU, B. c., 28.VI.1960, Aphis fabae, Rumex, Binodoxys angelicae, Lipolexis gracilis, Lysiphlebus fabarum ": $2 \hat{\sigma} \& 1$ \&; “60/440, Mnich. Hradiště, B.c., 1.VII.1960, Aphis fabae, Beta vulgaris": 19; "60/442, Praha, BZKU, B.c., 6.VII.1960, *Aphis farinosa, Salix, Binodoxys angelicae": 2+; "60/443, Praha, BZKU, B.c., 7.VII.1960, Brachycaudus, Prunus persica, Binodoxys angelicae, *Lysiphlebus $g r$. fabarum": 1ठ̋'; “60/443, Praha, BZKU, B. c., 
Fig. 1. Types of

Alloxysta antennae.

- a. Alloxysta arcuata.

- b. A. basimacula. - c.

A. brachyptera. - d. A. brevis. - e. A. castanea. - f. A. circumscripta. - g. A. citripes. - h. A. consobrina. - i. A. fracticornis. $-\mathrm{j}$. A. halterata. - k. A. hendrickxi. - I. A. kovilovicus. - m. A. leunisii. - n. A. macrophadna. - o. A. melanogaster. - p. A. mullensis. - q. A. nigricans. - r. A. obscurata. - s. A. pallidiconis. - t. A. pilipennis. - u. A. pilosa. - v. A. pleuralis. - w. A. postica. - x. A. pusilla. - y. A. ramulifera. - z. A. sawoniewiczi. - aa. A. semiaperta. - bb. A. victrix.
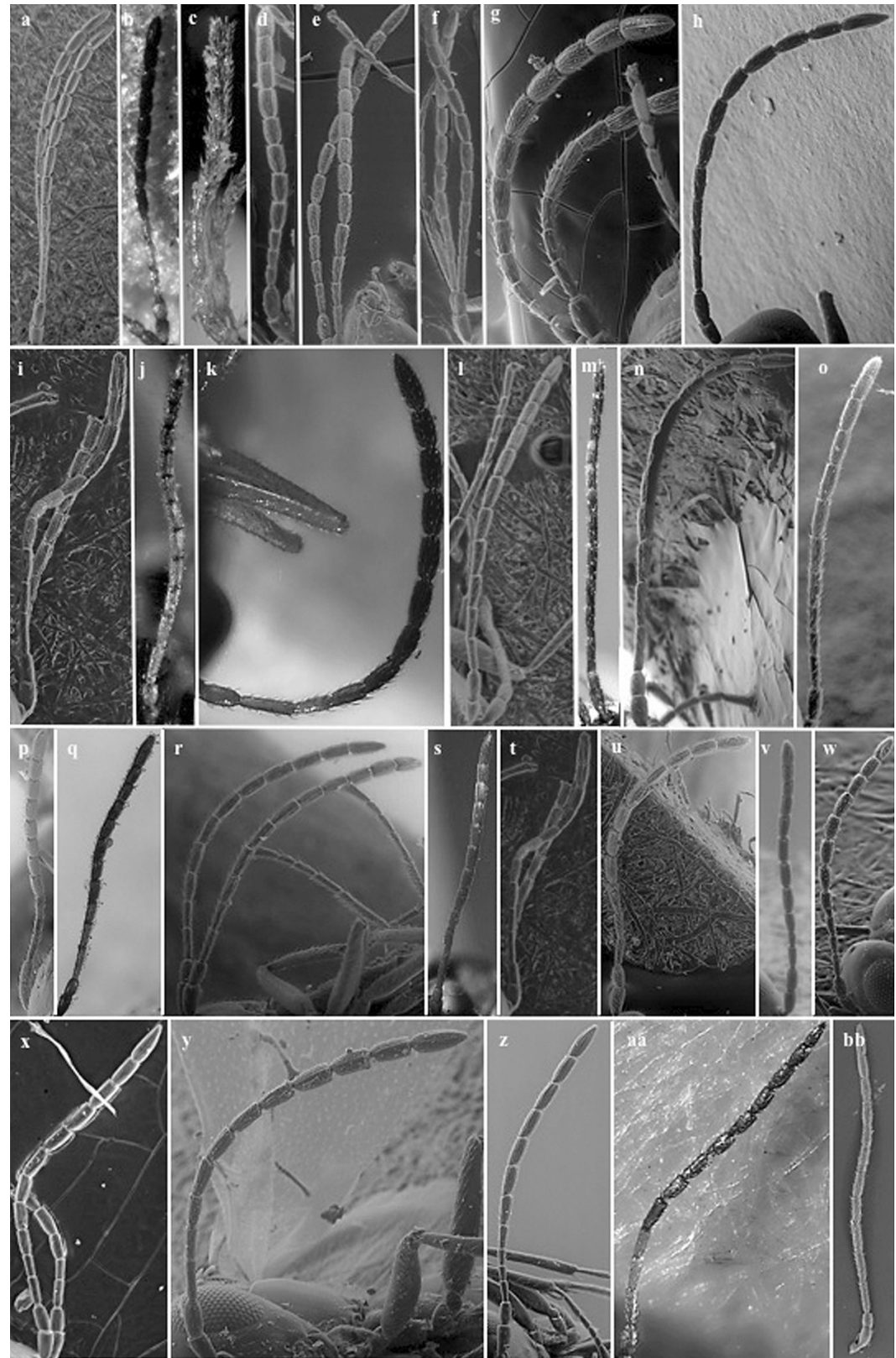

7.VII.1960, Brachycaudus, Prunus persica, Binodoxys angelicae, Ephedrus persicae": 10; "60/447, Praha, Seminářská zahrada, B. c., 8.VII.1960, Aphis, Laburnum vulgare": 10 \& 2.; "60/458, Mažice, B. m., 12.VII.1960, Aphis idaei, Rubus idaeus": 1ठ̋; "60/487, Praha, BZKU, B. c., 16.VII.1960, Anthemis sanctijohannis": 1ठ; "60/503, Praha, BZKU, B c, 16.VII.1960, Aphis, Rumex conglomeratus,

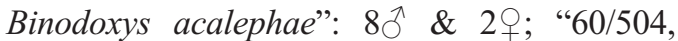

Praha, BZKU, B. c., 16.VII.1960, Aphis, Rumex flexuosus": 1ठ̄; "60/523, Dobřichovice, B. c., 26.VII.1960, Aphis, Rumex, Lysiphlebus fabarum ": 1ㅇ; "60/531, Dobřichovice, B. c., 26.VII.1960, Compositae”: 10̃; “60/543, Trněný Újezd, B. c., 26.VII.1960, Aphis fabae, Beta vulgaris, Lysiphlebus fabarum": 2 + ; “60/583, C. Brod, B. c. 28.VII.1960, *Brachycaudus cardui, Arctium lappa": 39;"60/585, Č. Brod, B c, 28.VII.1960, Aphis, Robinia pseudoacacia": 4§ో; 


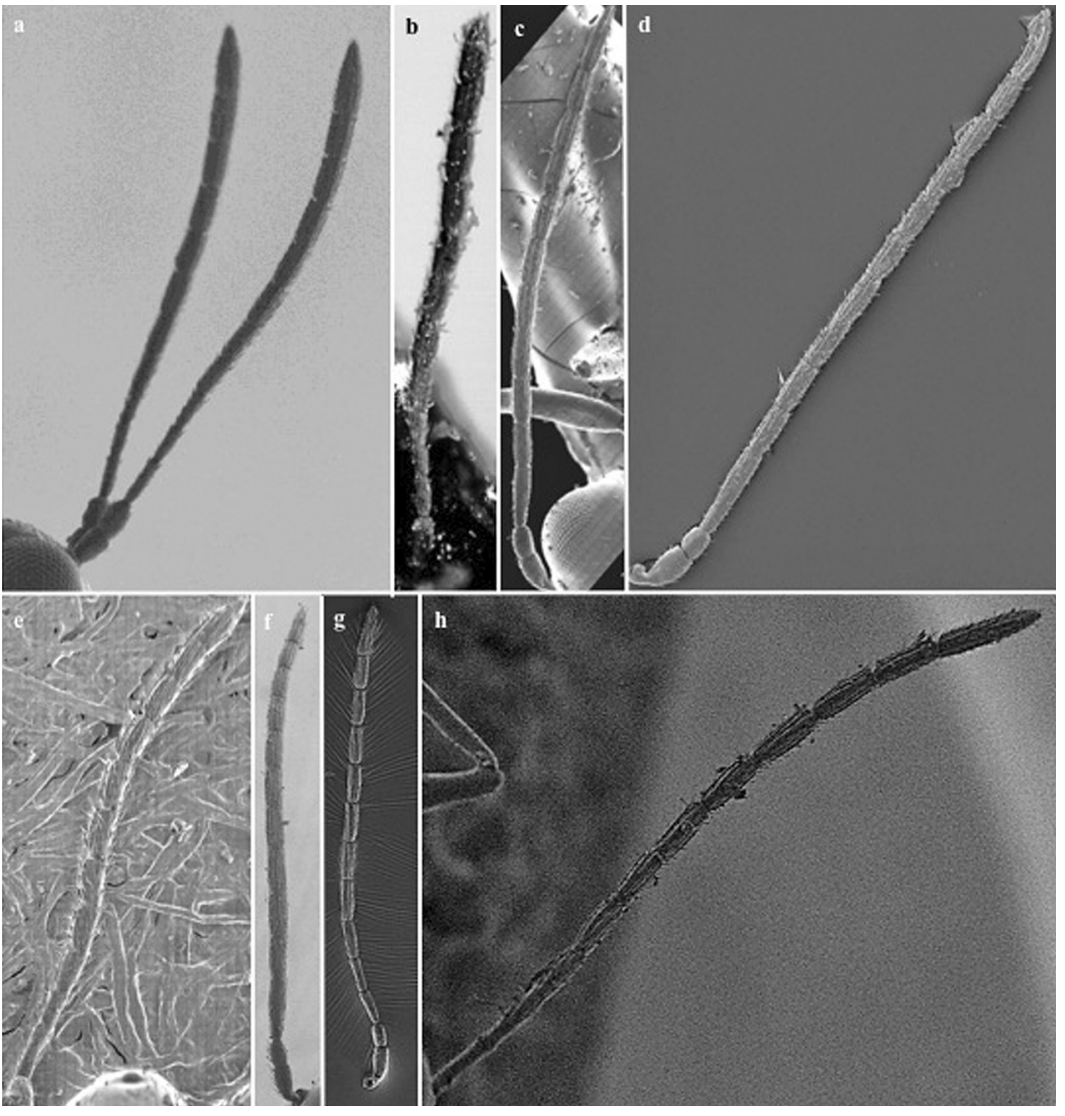

Fig. 2. Types of Phaenoglyphis antennae. - a. Phaenoglyphis evenhuisi. - b. P. heterocea. - c. P. longicornis. - d. P. ruficornis. - e. P. salicis. - f. P. stricta. - g. P. villosa. - h. P. xanthochroa.
"61/132 Praha, BZKU, B. c., 1.VI.1961, Aphis, Rhamus cathartica": 1q; "61/233, Královský Chlmec, Slov. or, 6.VI.1961, Myzus ligustri, Ligustrum, *Ephedrus cerasicola, *Monoctonus ligustri": 1\%; "61/245, Somotor, Slov. m, 7.VI.1961, Aphis fabae, Silene alba, Lysiphlebus fabarum": 3̊; "61/283, Svätoša, Slov. or., 8.VI.1961, Myzus cerasi, Prunus avium, Ephedrus persicae": 1q; "61/314, Piliš, Slov. N. Město, Slov. or., 9.VI.1961, *Aphis cichorii, Cichorium intybus, Lipolexis gracilis": 3 ; "61/349, Plešivec, Slov. or., 10.VI.1961, Aphis fabae, Papaver": 1 1̊’; “61/506, Štúrovo, Slov. m, 27.VI.1961, Hyadaphis, Conium maculatum, *Binodoxys brevicornis": 1ठ; “61/642, Pavlovské kopce, M. m., 3.VII.1961, Aphis fabae, Arctium”: 1우 “62/375, Žirovnice, B. m., VIII.1962, Aphis fabae, Cirsium”: 10 đ \& 1\%; "62/528, Smilovy hory, B. m., VIII.1962, Aphis fabae, Cirsium, Lysiphlebus fabarum ": 1; "64/150, Praha, B c, 22.VI.1964, Aphis nasturtii, Nasturtium, Binodoxys acalephae": $1 \delta^{\lambda} \& 1$ \%
"64/50, Bánovce, Slov.m., 30.V.1964, Aphis salviae, Salvia, Lipolexis gracilis": 19; "64/79, Luka p. Medníkem, B. c., VI.1964, Aphis brohmeri, Anthriscus silvestris, Lysiphlebus

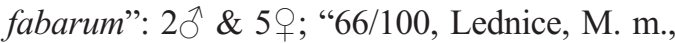
24.V.1966, Aphis urticata, Urtica dioica, Lysiphlebus fabarum": 3ᄋ; "66/127, Praha, Strahovská zahrada, B. c., 25.VI.1966, Euceraphis, Betula verrucosa": 3; "67/26, Český Krumlov, B. m., 8.VII.1967, *Microlophium carnosum, Urtica dioica, *Aphidius microlophii": 1+; "70/116, Valtice, M. m., 19.VI.1970, Aphis urticata, Urtica dioica, Lysiphlebus fabarum ": $2{ }^{\Uparrow}$ \& 2ᄋ; "70/98, Těchobuz, nr. Pacov, B. m., 15.VI.1970, *Lipaphis erysimi, Thlaspi arvense, *Ephedrus nacheri, *Praon volucre": 1; "71/11, Valtice M. m., 11.V.1971, *Rhopalosiphim insertum, Dysaphis plantaginea, Malus communis, *Ephedrus dysaphidis, *Monoctonus mali”: 2 + “71/137, Praha, Karlovo náměstí, B. c., 13.VII.1971, *Hyadaphis foeniculi, Lonicera 


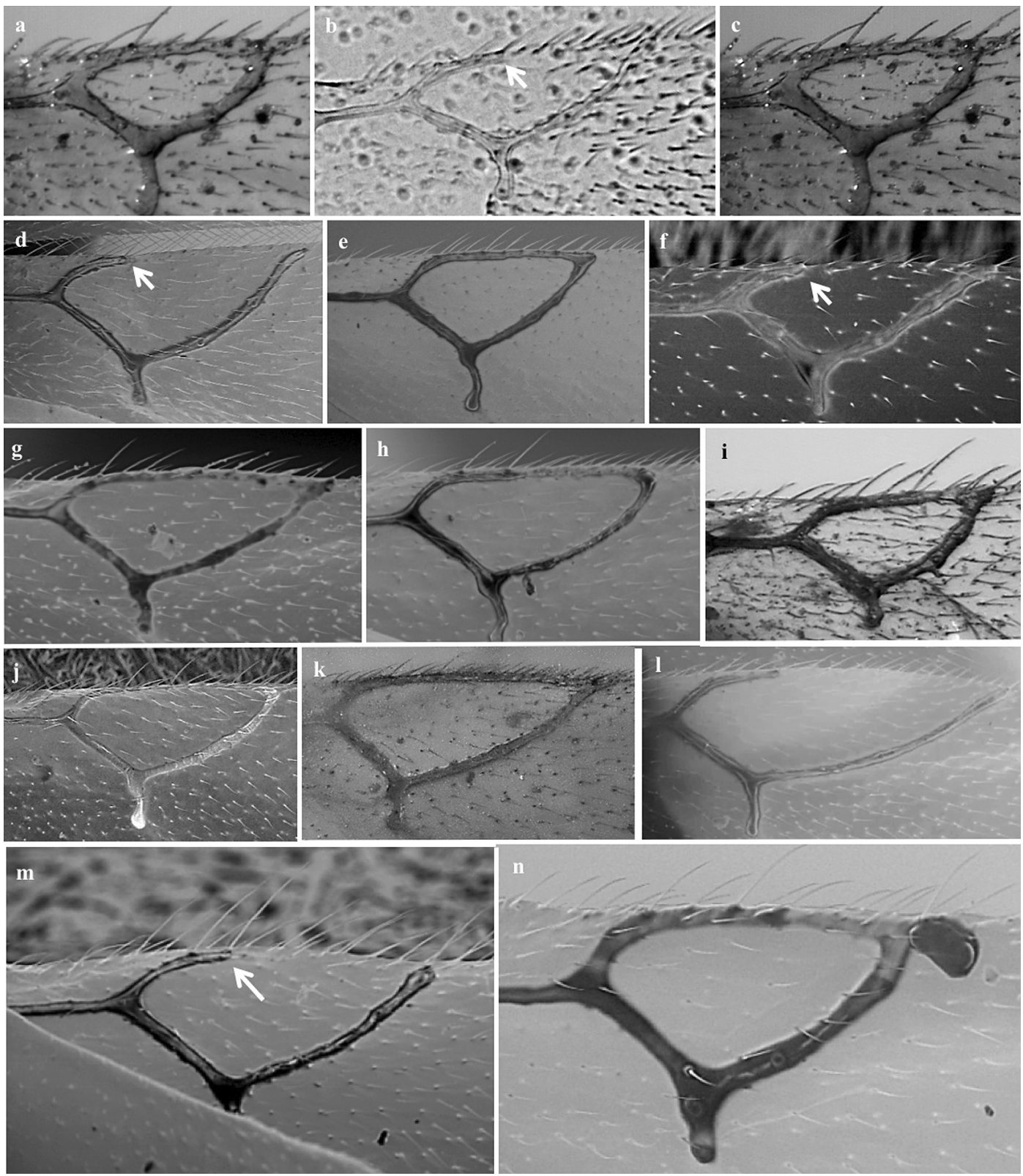

Fig. 3. Types of Alloxysta radial cell. - a. Alloxysta arcuata. - b. A. basimacula. - c. A. brevis. - d. A. castanea. - e. A. circumscripta. - f. A. citripes. - g. A. consobrina. - h. A. fracticornis. - i. A. hendrickxi. - j. A. kovilovicus. -k. A. leunisii. - I. A. macrophadna. - m. A. melanogaster. - n. A. mullensis.

xylosteum": 4つ \& 2ᄋ; “73/360, Těchobuz, B. m., 2.IX.1973, Impatientinum balsamines, Impatiens nollitangere": 1§`; “74/273, Praha, BZKU, B.c., 1.VII.1974, Myzus ligustri, Ligustrum, Ephedrus plagiator": 19; "74/321, Průhonice, B.c., 13.VII.1974, *Aphis pomi, Cotoneaster horizontalis, Binodoxys Angelicae": $1 \delta^{\Uparrow}$;
“74/349, Praha, BZKU, B.c., 9.VIII.1974, *Rhopalosiphum nymheae, Sagittaria, *Praon necans": 1ठ; "84/141, Jetřichovec, B.m., 6.VIII.1984, Aphis fabae, Cirsium arvense, *Lysiphlebus cardui": 10; "85/24, Lednice, M. m., 3.VII.1985, *Aphis intybi, Cichorium intybus, Lipolexis gracilis": $2 \hat{\bigcirc} \& 1$ \%; “85/25, 
Lednice, M.m., 3.VII.1985, Aphis fabae, Chenopodium, Binodoxys angelicae, Ephedrus nacheri, Ephedrus plagiator": 10; " $85 / 3$, České Budějovice, B.m., 17.VI.1985, *Aphis craccae, Vicia cracca, Binodoxys acalephae, *Praon abjectum": 1ठ; "85/46, Kojetín, M.c., 4.VII.1985, Aphis fabae, Arctium, Binodoxys acalephae": 10ึ; "87/123, Holašovice - Záboří, B.m., 19.VII.1987, Schizaphis typhaeae, Typha, Diaeretiella rapae, Ephedrus plagiator": 1\%; "58/231b, Praha, BZKU, B.c., 25.VII.1958, Aphis craccivora, Robinia pseudoacacia": 1 ; "60/360, Praha, Seminářská zahrada, B.c., 21.VI.1960, Aphis fabae, Philadelphus coronarius": 1\%; "60/422, Praha, BZKU, B.c.,

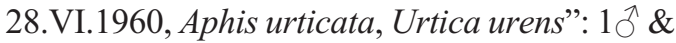
19; “61/63, Praha, Seminářská zahrada, B.c., 13.V.1961, Macrosiphum rosae, Rosa": $1 \delta^{\Uparrow} \&$ 2.; "62/32, Praha, Chuchle, B.c., 3.VI.1962, Myzus cerasi, Prunus avium, Ephedrus persicae": 1q; "71/29A, Karlštejn, B.c., 25.V. 1971, Dysaphis sp., Rhop.insertum, Malus communis,": 10 \& 5 ․ $5{ }^{\Uparrow} \& 5$ in UB.

Distribution. Holarctic, Neotropical and Oriental Regions (Ferrer-Suay et al. 2012a). New records for the Czech and Slovak Republics.

\subsection{Alloxysta basimacula (Cameron, 1886)}

Diagnosis. Alloxysta basimacula is mainly characterized having a completely open radial cell 3.0 times as long as wide (Fig. 3b), pronotal carinae present, propodeal carinae absent, beginning of rhinaria in F4, F1 longer than pedicel and subequal to F2, F2 longer than F3 and F3 shorter than F4 (Fig. 1b). It is similar to Alloxysta brachycera Hellén, 1963 but they can be differentiated by the relation between F1/F2: F1 subequal to F2 in A. basimacula (Fig. 1b) while $\mathrm{F} 1$ longer than $\mathrm{F} 2$ in $A$. brachycera; size of radial cell: 3.0 times as long as wide in $A$. basimacula (Fig. $3 \mathrm{~b}$ ) but 2.7 times as long as wide in $A$. brachycera.

Material studied. 1․ "74/292, Praha, Seminářská zahrada, B.c., 10.VII.1974, *Kallistaphis flava, Betula ": 1 in UB.

Distribution. Palaearctic (Ferrer-Suay et al. 2012a). New record for the Czech Republic.

\subsection{Alloxysta brachyptera (Hartig, 1840)}

Diagnosis. Alloxysta brachyptera is mainly characterized being a brachypterous species, with pronotal carinae absent, propodeal carinae present and F1 shorter than pedicel (Fig. 1c). It is similar to Alloxysta pedestris (Curtis, 1838) but can be easily differentiated by the presence of propodeal carinae: present in A. brachyptera while absent in $A$. pedestris.

Material studied. 3今̄. “61/197, Královský Chlumec, Slov. or, 5.VI.1961, Hydaphias, Galium verum": 1ठ; "83/48, Praha, Hanspaulka, B.c., 6.VII.1983, *Hayhurstia atriplicis, Chenopodium, *Diaeretiella rapae": 10ิ; "84/149, Pelhřimov, B.m., 8.VIII.1984, Undet. (green

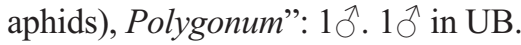

Distribution. Palaearctic (Ferrer-Suay et al. 2012a). New record for the Czech Republic.

\subsection{Alloxysta brevis (Thomson, 1862)}

Diagnosis. Alloxysta brevis is mainly characterized having a small closed radial cell 2.1 times as long as wide (Fig. 3c), pronotal carina absent (Fig. 5b), propodeal carinae present forming a plate, female and male antennae with the beginning of rhinaria in F4, F1 shorter than pedicel and F1-F3 subequal in length (Fig. 1c). It is similar to Alloxysta darci (Girault, 1933), can be differentiated by length of antennae: shorter than body in $A$. brevis while longer in $A$. darci; forewing with marginal setae shorter in $A$. brevis than in $A$. darci.

Material studied. 54へे \& 130․ " $57 / 107$, Lnáře, B.m., 5.VI.1957, *Aphis farinosa, Salix, *Binodoxys angelicae": $1 \overbrace{}^{\lambda} \& 19$; "57/204, Praha, Kinského sady, B.c., 16.VI.1957, Aphis fabae, Philadelphus": 2ᄋ; "57/96, Praha,BZKU, B.c., 3.VI.1957, Aphis fabae, Euonymus europaeus": 1Ỡ; "58/116, Praha, Seminářská zahrada, B.c., 8.VI.1958, *Aphis, Spirea": 1; "58/181, Opatov, nr. Svitavy, B. or. 8.VII.1958, Aphis fabae, Beta vulgaris, *Binodoxys acalephae": 3o; "58/21, Filákovo, Slov.m. 22.V.1958, *Aphis sambuci, Sambucus nigra": 1 đ̊ \& 1; “"58/241, Karlštejn, B.c. 2.VIII.1958, Aphis fabae, Lappa major, *Lysiphlebus fabarum ": 2q; "58/29, Šíd, Fil'ákovo, Slov.m., 22.V.1958, Aphis fabae, Euonymus europaeus": 
1 đิ \& 19; "58/334, Turňa a. B., Slov.m., 15.X.1958, Aphis fabae, Evonymus europaeus, Binodoxys angelicae": 2O; "58/35, Š́d, Fil'ákovo, Slov.m., 22.V.1958, Aphis fabae, Euonymus europaeus": $1 \widehat{\delta} \& 1$ \&; "58/47, Humenné, Jasenský Hrad, Slov. or., 25.V.1958, Aphis fabae, Euonymus europaeus": $10^{\wedge} \& 2$; "58/59, Kamienka, nr. Humenné, Slov.or., 25.V.1958, Viburnum": 1 đ̊ \& 1q; "58/61, Pusté Čemerné, nr. Michalovice, Slov. or., 26.V.1958, Aphis fabae, Euonymus europaeus": 3 q; "58/79, Trenčín, Slov.occ., 29.V.1958, Aphis, Spirea, Binodoxys angelicae": 19; "59/112, Praha, BZKU, B.c., 9.VI.1959, *Aphis viburni, Viburnum opulus, Binodoxys angelicae": $1 \delta^{\lambda} \& 3$; "59/116, Praha, BZKU, B.c., 9.VI.1959, *Aphis pomi, Malus communis, Binodoxys angelicae":

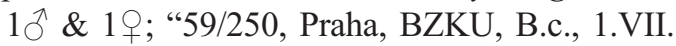
1959, Aphis fabae, Campanula rapunculoides, Lysiphlebus fabarum ": 19; "59/49, Martin, Slov.c., 18.V.1959, Aphis fabae, Euonymus europaeus, Binodoxys angelicae": 1今̄; "60/115, Čelákovice B.c., 26.V.1960, Hydaphias, Galium mollugo, *Aphidius matricariae": $10^{\uparrow}$ \& 1 \% "60/164, Král.Chlmec, Slov. or., 1.VI.1960, Aphis, Onobrychis sativa, Binodoxys acalephae": 19; “60/2, Malá Jiz. Louka, Jizerské hory, B.bor., 19.V.1960, Cinara sp., Pinus uncinnata": 29; "60/320, Praha, Seminářská zahrada, B.c., 12.VI.1960, Aphis urticata, Urtica dioica, Binodoxys acalephae": 19; "60/338, Praha, BZKU, 15.VI.1960, Aphis fabae, Arctium, Binodoxys angelicae, Lysiphlebus fabarum": 1 ; "60/401, Praha, BZKU, B. c, 25.VI.1960, Polygonum amphibicum": 1ठ; "60/404, Praha, BZKU, B. c., 25.VI.1960, Trifolium fragiferum": 19; "60/405, Praha, BZKU, B.c., 25.VI.1960, Aphis farinosa, Salix repens rosmarinifolia, Binodoxys angelicae, *Lysiphlebus cardui”: $2 \hat{0}$ \& 19; "60/420, Praha, BZKU, B. c., 29.VI.1960, Aphis fabae, Beta vulgaris, Lysiphlebus fabarum": 1ð \& 4; "60/424, Praha, BZKU, B. c., 28.VI.1960, Aphis fabae, Rumex, Binodoxys angelicae, Lipolexis gracilis, Lysiphlebus fabarum": $3{ }^{\lambda} \&$ 3 0 ;"60/440, Mnich. Hradiště, B.bor., 1.VII.1960, Aphis fabae, Beta vulgaris": 1; " "60/442, Praha, BZKU, B. c., 6.VII.1960, Aphis farinosa, Salix, Lysiphlebus cardui": $1 \delta^{\Uparrow} \&$ 19; "60/443, Praha, BZKU, B. c., 7.VII.1960, Brachycaudus, Prunus persica, Binodoxys angelicae, Ephedrus persicae": 1ठ; "60/458, Mažice, B. m., 12.VII.1960, *Aphis idaei, Rubus idaeus": 1; "60/485, Praha, BZKU, B. c., 16.VII.1960, Aphis, Laburnum anagyroides, Binodoxys angelicae": 50 \& 2ᄋ; "60/49, Srbsko, B. c., 25.III.1960, Aphis, Therioaphis, Medicago sativa, Lipolexis gracilis": $1 \jmath^{\Uparrow} \& 4$ 우 “60/494, Praha, BZKU, B. c., 16.VII.1960, Aphis, Arnica sacchaliensis": 10̄ \& 1; "60/502, Praha, BZKU, B. c., 16.VII.1960, Aphis, Tropaeolum majus, Binodoxys angelicae": $2 \hat{\sigma} \& 1 \%$; "60/503, Praha, BZKU, B.c., 16.VII.1960, Aphis, Rumex conglomeratus, Binodoxys acalephae": 2ᄋ; "60/504, Praha,BZKU, B. c., 16.VII.1960, Aphis, Rumex flexuosus": 2q; "60/505, Praha, BZKU, B. c., 16.VII.1960, Aphis, Rumex

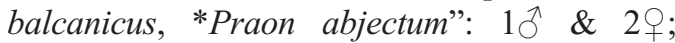
"60/506, Praha, BZKU, B. c., 16.VII.1960, Aphis, Rumex nepalensis": 1 ${ }_{0}^{\lambda}$; “60/507, Praha, BZKU, B. c., 16.VII.1960, Aphis, Rumex salicifolius": 2O; "60/509, Praha, BZKU, B.c., 16.VII.1960, Rheum compactum”: 1 q; “60/514, Praha, BZKU, B. c., 20.VII.1960, Aphis fabae, Beta vulgaris": 1 đ’; "60/519, Dobřichovice, B. c., 26.VII.1960, Cryptosiphum, Artemisia vulgaris, *Ephedrus nacheri”: 2ᄋ; “60/523, Dobřichovice, B c, 26.VII.1960, Aphis, Rumex,

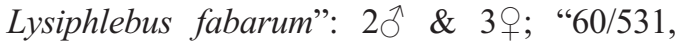
Dobřichovice, B. c., 26.VII.1960, Compositae": 1; " $60 / 581$, Č. Brod, B. c., 28.VII.1960, Hyadaphis, Conium maculatum, *Ephedrus plagiator, *Binodoxys brevicornis, Praon volucre": 1q; "60/586, Praha, BZKU, B. c., 30.VII.1960, Aphis, Robinia pseudoacacia, Binodoxys angelicae, Lysiphebus cardui": $1 \delta^{\Uparrow} \&$ 1 \%,"60/587, Praha, BZKU, B. c., 30.VII.1960, Aphis farinosa, Salix, Lysiphlebus cardui": 1 § \& 19; "61/132, Praha,BZKU, B. c., 1.VI.1961, Aphis, Rhamus cathartica": 1q; "61/231, Královský Chlmec, Slov. or, 6.VI.1961, Brachycaudus, Achillea millefolium, *Aphidius absinthii”: 20̛; “61/314, Piliš, Slov. N. Město, Slov. or., 9.VI.1961, *Aphis cichorii, Cichorium intybus, *Lipolexis gracilis": 2ᄋ; "61/416, Praha, Seminářská zahrada, B. c., 20.VI.1961, Aphis, Spirea": 1 ;; "61/428, Praha, BZKU, B. c., 21.VI.1961, *Aphis pomi, Crataegus monogyna, Ephedrus plagiator": $10^{\Uparrow}$ \& 1우 “61/506, Śtúrovo, Slov m, 27.VI.1961, Hyadaphis, Conium maculatum, Binodoxys brevicornis": 
1우 “61/56, Praha, Seminářská zahrada, B. c., 13.V.1961, Aphis fabae, Philadelphus coronarius, Binodoxys angelicae": 19; "61/66, Praha, BZKU, B. c., 15.V.1961, Aphis, Viburnum opulus, Binodoxys angelicae, *Praon abjectum": 1§̄; "61/664, Mikulov, M. m., 4.VII.1961, Hyadaphis passerinii, Lonicera caprifolium": $1 \hat{\sigma}^{\text {त } \& ~ 1 ㅇ ㅜ ~ " ~} 62 / 528$, Smilovy hory, B. m., VIII.1962, Aphis fabae, Cirsium, Lysiphlebus fabarum": 4; "63/780, Belanské Tatry, Slov.bor., 6.VIII.1963, *Macrosiphum rosae, Aphis fabae, Valeriana oficinalis, *Ephedrus plagiator": 2ᄋ; "64/150, Praha, B. c., 22.VI.1964, *Aphis nasturtii, Nasturtium, Binodoxys acalephae": 2ð \& 2ᄋ; "64/79, Luka p. Medníkem, B. c., VI.1964, *Aphis brohmeri, Anthriscus silvestris, Lysiphlebus cardui 2\%; "66/100, Lednice, M. m., 24.V.1966, *Aphis urticata, Urtica dioica, Lysiphlebus fabarum ": 2ᄋ; "70/209, Jičín, B. or., 20.VIII.1970, Aphis fabae, Yucca, Lysiphlebus fabarum": 5; "71/137, Praha, Karlovo náměstí, B. c., 13.VII.1971, *Hyadaphis foeniculi, Lonicera xylosteum": 1q; "71/164, Karlštejn, B. c., 21.VII.1971, *Aphis intybi, Cichorium intybus, Lysiphlebus fabarum": 19; “71/67, Kroměříž, M. or., 7.VI.1971, Aphis urticata, Urtica dioica, Binodoxys acalephae": 19; "72/142, Hustopeče, M. m., 7.VI.1972, Galiobium, Galium": 1ð’; “74/116, Praha, Seminářská zahrada, B.c., 7.VI.1974, *Aphis spiraephaga, Spirea, Binodoxys angelicae": 1ठ \& 19; “74/242, Lipt. Ján, Slov.bor., 25.VI.1974, Cryptosiphum, Artemisia vulgaris, Lipolexis gracilis": 5 +; "74/273, Praha, BZKU, B.c., 1.VII.1974, * Myzus ligustri, Ligustrum, Ephedrus plagiator": 19; “74/332, Praha, BZKU, B.c., 24.VII.1974, * Rhopalosiphum nymheae, Caltha palustris and other aquatic plants, *Praon necans": 10; "74/343, Praha, BZKU, B.c., 28.VII.1974, Rhopalosiphum nymheae, Sagittaria, *Aphidius colemani, Praon necans": $1 \delta^{\widehat{ }} \& 1$ 1 ; “74/348, Praha, BZKU, B.c., 9.VIII.1974, *Rhopalosiphum nymheae, Sagittaria, Praon necans": 1\%; "80/14, Př́bram, B.c., 2.VII.1980, Aphis urticata, Urtica dioica, Binodoxys acalephae": 20 \& 5q; "83/48, Praha, Hanspaulka, B.c., 6.VII.1983, *Hayhurstia atriplicis, Chenopodium, Diaeretiella rapae": 1 \%; "83/50, České Budějovice, B.m., 13.VIII.1983, Aphis fabae, Cirsium arvense": 10 \& 1 우 "83/55, Brloh, Blanský les, B.m., 14.VII.1983, *Aphis jacobaeae, Senecio, *Lipolexis gracilis": $10^{1}$ \& 2 \%; " $85 / 3$, České Budějovice, B.m., 17.VI.1985, *Aphis craccae, Vicia cracca, Binodoxys acalephae, *Praon abjectum": 50 ^ \& 2ᄋ; "89/160, Prachatice, B.m., 22.VI.1989, Cryptosiphum, Coloradoa, Artemisia vulgaris, *Aphidius arvensis, *Ephedrus nacheri": 89; “89/172, České Budějovice, B.m., 28.VI.1989, Aphis fabae, Cirsium arvense, Binodoxys angelicae, Lysiphlebus cardui": 2o; "60/399, Praha, BZKU, B.c., 24.06.1960, Aphis, Arnica montana": 2q; "60/422, Praha, BZKU, B.c., 28.VI.1960, Aphis urticata, Urtica urens": 10 \& 5q; "61/287, Svätoša, S.or., 8.VI.1961, Aphis fabae, Chenopodium": 1 + $5 \hat{\jmath} \& 5 \bigcirc$ in UB.

Distribution. Holarctic, Neotropical and Oriental Regions (Ferrer-Suay et al. 2012a). New records for the Czech and Slovak Republics.

\subsection{Alloxysta castanea (Hartig, 1841)}

Diagnosis. Alloxysta castanea is mainly characterized by having a partially open radial cell 2.4 times as long as wide (Fig. 3d), pronotal and propodeal carinae present, male and female with the beginning of rhinaria in F3, F2-F4 subequal in length (Fig. 1e), F1 and F2 slightly curved in male. It is similar to Alloxysta aurata Belizin, 1968 but can be differentiated by the relation between F2 and F3: F2 subequal to F3 in $A$. castanea (Fig. 1e) but F2 shorter than F3 in $A$. aurata; and size of the radial cell: 2.4 times as long as wide in A. castanea (Fig. $3 \mathrm{~d}$ ) while 3.0 times in A. aurata.

Material studied. $16 \hat{\jmath} \& 29 \circ$. "58/116, Praha, Seminářská zahrada, B.c., 8.VI.1958, *Aphis, Spirea": 1ठ; "58/125, Čeňkova pila, Šumava, B. occ, 3.V.1958, *Rhopalosiphum padi, Prunus padus, *Ephedrus plagiator": $2 \circ$; "58/38, Š́d, Fil'ákovo, Slov.m., 22.V.1958, Myzaphis rosarum, Macrosiphum rosae, Rosa, *Ephedrus laevicollis, Ephedrus plagiator, Praon volucre": 2ᄋ; "59/113, Praha, BZKU, B.c., 9.VI.1959, *Liosomaphis berberidis, Berberidis vulgaris": 10; "59/201, Katovice, B. occ., 25.VI.1959, *Macrosiphum rosae, Rosa sp., Praon volucre": 1우 "59/226, Mirotice, B.m., 26.VI.1959, Cryptomyzus, Ribes rubrum": 
3o; " $59 / 291$, Mnichová, Orl.hory, B. or., 8.VII.1959, Cavariella sp., Salix, 1; " $59 / 42$, Martin, Slov.c., 18.V.1959, Rhopalosiphum padi, Prunus padus, Ephedrus plagiator": 10; "59/80, Praha, Seminářská zahrada, B.c., 24.V.1959, Hyperomyzus, Grossularia, Ephedrus plagiator, Praon volucre": 1\%; "60/111, Čelákovice B.c., 26.V.1960, Aulacorthum, Potentilla argentea, *Aphidius urticae, Ephedrus plagiator": 2+; "60/264, Javorník, M, or., 7.VI.1960, *Macrosiphum euphorbiellum, Euphorbia amygdaloides": 1今ో; "60/575, Č. Brod, B. c., 28.VII.1960, Hyalopterus pruni, Phragmites communis, Praon volucre": 1今'; "60/616, Prachov, B. bor., 2.VIII.1960, *Rhopalosiphoninus, Oxalis acetosella": 10̄; "60/620, Prachov, B.bor. 2.VIII.1960, Rhopalosiphoninus, Oxalis acetosella, *Ephedrus

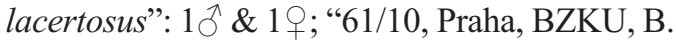
c., 2.V.1961, *Ceruraphis eriophori, Viburnum lantana, Binodoxys angelicae": 1今̄; "61/164, Královský Chlmec, Slov. or, 5.VI.1961, *Phorodon humuli, Humulus lupulus, *Lysiphlebus cardui": 19; "61/204, Královský Chlmec, Slov. or, 6.VI.1961, Hyalopterus pruni, Prunus domestica, Praon volucre": 1ठ; "61/224, Královský Chlmec, Slov. or, 6.VI.1961, Macrosiphum rosae, Rosa, Aphidius rosae": 10; "61/35, Český Krumlov, B. m., 10.V.1961, *Aphis fabae, Euonymus europaeus, Ephedrus plagiator": 1ठð;; “62/24, Lovoš, Č. Středohoří, B. bor., 31.V.1962, Ceruraphis eriophori, Viburnum opulus, Ephedrus plagiator”: 10'; “62/469, Putimov, nr. Pelhřimov, VIII.1962, Sitobion avenae, Avena sativa, *Aphidius uzbekistanicus, Ephedrus plagiator": 19; "63/664, Hostýn, Hostýnské vrchy, M.or., 15.VII.1963, Macrosiphum, Prenanthes purpurea, Aphidius urticae, Ephedrus plagiator": 19; "66/197, Lednice, M. m., 14.VII.1966, Hyalopterus, Phragmites communis, *Aphidius transcaspicus": 1+; "67/39, Mladá Vožice, Šelmberk, B. m., 27.VIII.1967, Euphorbia, Praon volucre": 1q; "71/34, Praha, BZKU, B. c., 24.V.1971, Ovatus, Crataegus monogyna, Ephedrus plagiator": $1 \AA$ \& 7우 "74/156, Dolina 7prameňov, Bel. Tatry, Slov.bor., 20.VI.1974, Betulaphis, Betula, *Aphidius aquilus": 19; "74/249, Lipt.Ján, Slov.bor., 25.VI.1974, Cavariella, Salix, *Aphidius salicis": 20;
"70/110, Rusava, Hostýnské vrchy, M.or., 17.06.1970, Cavariella, Salix”: $1 ð$ \& 3․ $3 ð$ \& 5 ㅇ in UB.

Distribution. Holarctic, Neotropical and Oriental Regions (Ferrer-Suay et al. 2012a). New records for the Czech and Slovak Republics.

\subsection{Alloxysta circumscripta (Hartig, 1841)}

Diagnosis. Alloxysta circumscripta is mainly characterized by having a closed radial cell 2.3 times as long as wide (Fig. 3e), pronotal carinae present, propodeal carinae absent, female antennae with the beginning of rhinaria in F5, F2 shorter than F3, F3 shorter than F4 (Fig. 1f), male antennae with the beginning of rhinaria in F4, F2 longer than F3, F3 shorter than F4. It is similar to Alloxysta consobrina (Zetterstedt, 1838) but can be differentiated by the proportions among flagellomeres: F1 subequal to F2, F2 shorter or subequal to F3 in $A$. circumscripta (Fig. 1f) while $\mathrm{F} 1$ longer than $\mathrm{F} 2, \mathrm{~F} 2$ subequal to $\mathrm{F} 3$ in $A$. consobrina (Fig. 1h); size of radial cell: 2.5 times as long as wide in A. circumscripta (Fig. $3 \mathrm{e}$ ) but 2.7 in $A$. consobrina (Fig. 3g).

Material studied. 20 \& \& 5․ "57/96, Praha, BZKU, B.c., 3.VI.1957, *Aphis fabae, Euonymus europaeus": 20; "60/20, BZKU, B.c., 17.V.1960, Aphis fabae, Euonymus europaeus, *Binodoxys angelicae, *Praon abjectum": 5 ㅇ. $10 \hat{0} \& 3$ in UB.

Distribution. Palaearctic (Ferrer-Suay et al. 2012a). New record for the Czech Republic.

\subsection{Alloxysta citripes (Thomson, 1862)}

Diagnosis. Alloxysta citripes is mainly characterized by having a partially open small radial cell 2.1 times as long as wide (Fig. 3f), pronotal carinae present, propodeal carinae present forming a plate but not protruding, female antennae with the beginning of rhinaria in F4, F1 subequal to pedicel and longer than F2, F2-F4 subequal in length (Fig. 1g), male antennae with the beginning of rhinaria in F1, pedicel-F3 subequal, F3 slightly shorter than F4. It is similar to Alloxysta postica (Hartig, 1841) but can be differentiated by the shape of the propodeal carinae: they are not protruding in $A$. citripes while they are clearly visible and forming a protruding plate in $A$. 


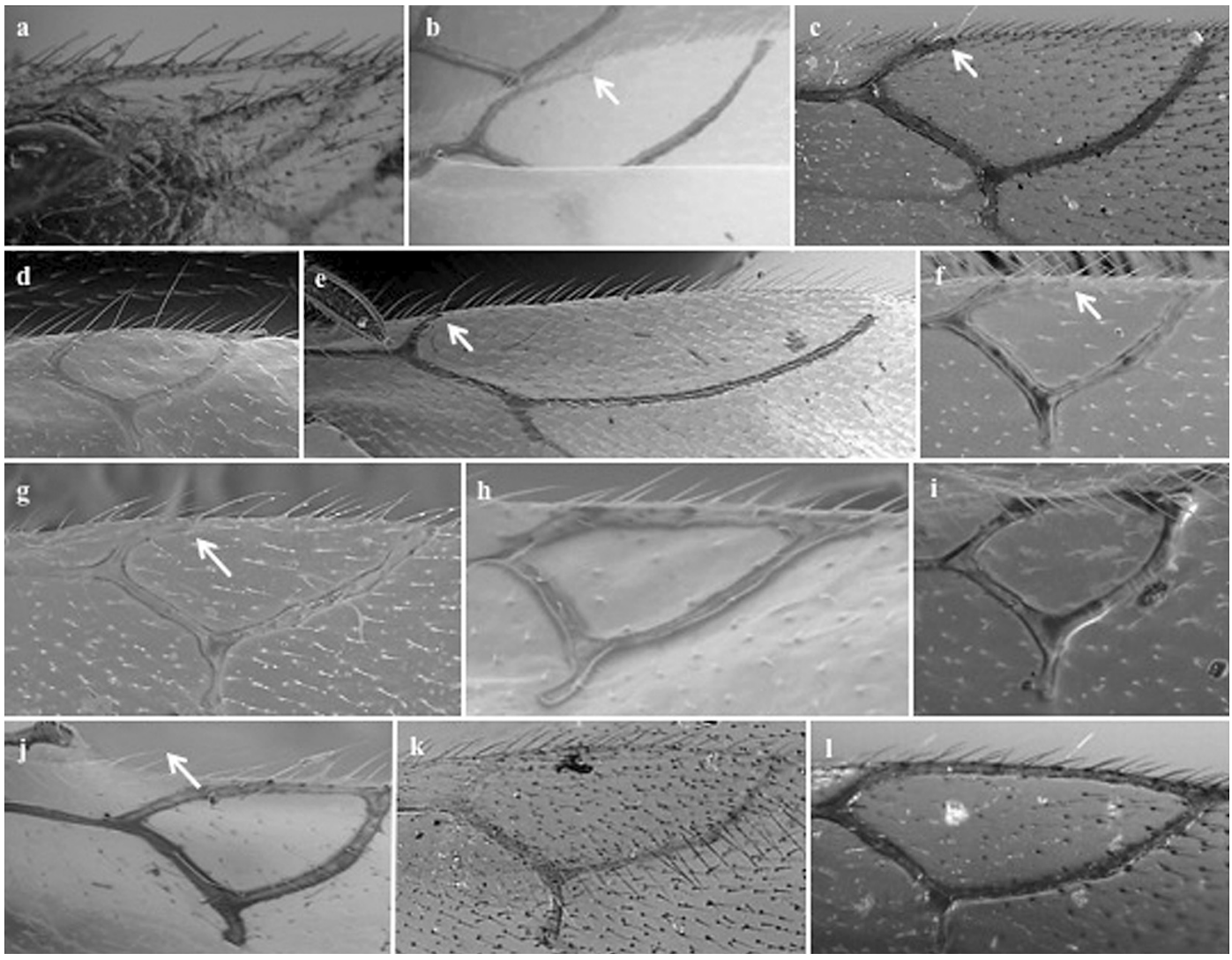

Fig. 4. Types of Alloxysta radial cell. - a. A. nigricans. - b. A. obscurata. - c. A. pallidiconis. - d. A. pilipennis. - e. A. pilosa. - f. A. pleuralis. - g. A. postica. - h. A. pusilla. - i. A. ramulifera. - j. A. sawoniewiczi. - k. A. semiaperta. - I. A. victrix.

postica; size of radial cell: 2.1 times as long as wide in $A$. citripes (Fig. 3f) but 2.5 times as long as wide in $A$. postica (Fig. 4g).

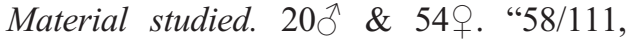
Praha, BZKU, B. c., 30.V.1958, Eucallipterus tiliae, Tilia tomentosa, *Praon flavinode, *Trioxys curvicaudus": 19; "58/228, Komárov, B. or., 23.VII.1958, *Aphis cognatella, Euonymus europaeus, *Binodoxys angelicae": $1 \hat{\jmath}$; "58/269, Sušice, B.m., 12.VIII.1958, *Brachycaudus cardui, Carduus nutans, ${ }^{*}$ Lysiphlebus gr. fabarumi": 1ठ; "60/362, Praha, Kinského sady,B. c., 21.VI.1960, Myzocallis, CarPinus” : 1q; "60/411, Praha, Vojanovy sady, B.c., 26.VI.1960, Eucallipterus tiliae, Tilia, Trioxys pallidus, Trioxys curvicaudus": $2{ }^{\wedge} \& 1$ \& "60/418, Praha Strahovská zahrada, B. c., 27.VI.1960, M. only, Quercus, Trioxys curvicaudus": 19; "60/546, Trněný Újezd, B. c., 26.VII.1960, Thelaxes, Quercus”: 19; “60/595,
V. Ježov, B. m., Drepanosiphum, Acer pseudoplatanus, *Trioxys cirsii”: 1; “60/668, Praha, Nábřeží Legií, B. c., 25.VIII.1960, Periphyllus, Drepanosiphum, Acer pseudoplatanus": 6웅 “60/673, Těchobuz, nr.Pacov, B. m., 30.VIII. 1960, Periphyllus, Drepanosiphum, Acer pseudoplatanus": 1q; “60/681, Kováčov, Slov. m,. 31.VIII.1960, Hoplocallis ruperti, Quercus ilex": 1+; "61/220, Královský Chlmec, Slov. or, 6.VI.1961, M. only, Quercus, Trioxys pallidus": 19; "61/406, Praha, Semináŕská zahrada, B. c., 20.VI.1961, Tuberculatus annulatus, Quercus, Trioxys pallidus": 1 . ; “61/420, Praha, BZKU, B c, 21.VI.1961, Quercus, Trioxys pallidus": 2今; "61/421, Carpinus betulus, Praha, BZKU, B. c., 21.VI.1961, *Myzocallis carpini, Trioxys pallidus": 1; " "61/473, Praha, Kinského sady, B. c., 25.VI.1961, Eucallipterus tiliae, Tilia, Trioxys curvicaudus": 1+;"68/368, Praha, Seminářská zahrada, B c, 12.VIII.1968, *Drepanosiphum 
platanoides, Acer pseudoplatanus": 1; "69/107, Praha, Kinského sady, B. c., 17.VI.1969, Tuberculatus, Quercus, Praon flavinode": 29; “69/199, Těchobuz, nr. Pacov, B. m., 8.VII.1969, Drepanosiphum, Acer pseudoplatanus": 1; “69/30, Praha, Seminářská zahrada, B. c., 23.V.1969, Drepanosiphum, Acer pseudoplatanus": 1우 "69/89, Těchobuz nr. Pacov, B. m., 8.VI.1969, Drepanosiphum, Acer pseudoplatanus, Falciconus pseudoplatani, Trioxys cirsii”: 19; “74/119, Praha, Seminářská zahrada, B.c., 7.VI.1974, *Myzocallis carpini, Carpinus, Trioxys pallidus": 2+; "74/133, Praha, BZKU, B.c., 12.VI.1974, Myzocallis carpini, Carpinus betulus, Trioxys pallidus": $1 \delta^{\top} \& 1$ 웅 "74/200, Stankovany, Choč.pohorie, Slov.bor., 24.VI.1974, Eucallipterus tiliae, Tilia": 10̄; "82/12, Pacov, B.m., 22.VI.1982, Myzocallis coryli, Corylus, Trioxys tenuicaudus": $2 \widehat{\bigcirc} \& 1$; "83/15, České Budějovice, B.m., 8.VI.1983, Tuberculatus, Quercus, Trioxys pallidus": $3 \hat{\jmath}$ \& 6ㅇ; "83/29, České Budějovice, B.m., 24.VI.1983, Eucallipterus tiliae, Tilia": $2 \widehat{ }$ \& \& 2ᄋ; "84/16, České Budějovice, B.m., 16.VI.1984, Tuberculatus, Quercus, Trioxys pallidus, *Trioxys tenuicaudus": 2+; "84/4, Znojmo, M.m., 5.VI.1984, Chromaphis juglandicola, Juglans regia, Trioxys pallidus": 1 đิ \& 2ᄋ; "84/44, Hluboká nad Vltavou, B.m., 21.VI.1984, Myzocallis, Carpinus, Trioxys pallidus, Trioxys tenuicaudus": 5; "84/44, Hluboká nad Vltavou, B.m., 21.VI.1984, Myzocallis, Carpinus, Trioxys tenuicaudus": $10^{\wedge}$ \& 2ᄋ; "84/61, Čimelice, B.c., 28.VI.1984, Tuberculatus, Quercus, Trioxys tenuicaudus": $1 \delta$ \& 3ㅇ; "84/78, České Budějovice, B.m., 3.VII.1984, Tuberculatus, Quercus, Praon flavinode, Trioxys pallidus": 19; "84/79, České Budějovice, B.m., 3.VII.1984, Tinocallis, Ulmus, Trioxys tenuicaudus": 1ðð; "84/80, České Budějovice, B.m., 5.VII.1984, Eucallipterus tiliae, Tilia, Trioxys tenuicaudus": 10 \& 1 \% "84/89, Pacov, B.m., 10.VII.1984, Myzocallis, Corylus": 19; "85/27, Lednice, M.m., 3.VII.1985, Aphis fabae, Cirsium arvense": 1 ㅇ. 50 \& 5 क in UB.

Distribution. Palaearctic (Ferrer-Suay et al. 2012a). New records for the Czech and Slovak Republics.
3.8. Alloxysta consobrina (Zetterstedt, 1838)

Diagnosis. Alloxysta consobrina is mainly characterized by having a closed radial cell 2.7 times as long as wide (Fig. 3g), pronotal carinae present, propodeal carinae absent, male and female antennae with the beginning of rhinaria in F4, F2 longer than F3, F3 shorter than F4 (Fig. 1h), F1$\mathrm{F} 3$ bowed in male. It is similar to $A$. circumscripta but can be differentiated by the proportions among flagellomeres: F1 longer than F2, F2 subequal to F3 in A. consobrina (Fig. 1h) while $\mathrm{F} 1$ subequal to $\mathrm{F} 2, \mathrm{~F} 2$ shorter or subequal to $\mathrm{F} 3$ in A. circumscripta (Fig. 1f); size of radial cell: 2.7 times as long as wide in A. consobrina (Fig. $3 \mathrm{~g}$ ) but 2.5 in $A$. circumscripta (Fig. 3e).

Material studied. 43ð \& 88․ "57/156, Karlštejn, B.c., 12.VI.1957, Aphis fabae, Chenopodium bonus-henricus, *Lysiphlebus fabarum": $1 \delta$ \& 1우 "57/96, Praha, BZKU, B.c., 3.VI.1957, Aphis fabae, Euonymus europaeus": 19; "59/226, Mirotice, B.m., 26.VI.1959, Cryptomyzus, Ribes rubrum": $3{ }^{\lambda}$ \& 3 \% "59/358, Krč, B.m., 24.VII.1959, *Acyrthosiphon pisum, Trifolium pratense, *Aphidius ervi": 2ð’;"60/251, Strážnice, M m, 6.VI.1960, *Aphis urticata, Urtica dioica": $2 \widehat{0}$ \& 7O; “60/341, Raná, Luony, B.c., 17.VI.1960, Brevicoryne brassicae, Sinapis arvensis, Diaeretiella rapae": 1ठ \& 8; “60/36, Rajhrad, M. m., 19.V.1960, Brevicoryne brassicae, Brassica napus, Diaeretiella rapae": 10 \& \& 6우 "60/36, Rahrad, M. m., 19.V.1960, Brevicoryne brassicae, Brassica napus, Diaretiella rapae": $2 \widehat{\gamma} \& 3$; ; "60/389, Praha. BZKU, B c, 24.VI.1960, Cavariella, Daucus carota, Aphidius salicis, *Binodoxys brevicornis": 1\%; "60/477, Praha, Strahovská zahrada, B. c., 10.VII.1960, Brevicorne brassicae, Brassica oleracea capitala, Diaretiella rapae": $2 \widehat{\bigcirc} \& 2$; "60/547, Trněný Újezd, B. c., 26.VII.1960, Brevicoryne brassicae, Brassica oleracea": $2 \widehat{ }$ \& 5; "60/549, Trněný Újezd, B. c., 26.VII.1960, Brevicoryne brassicae, Brassica oleracea var., Diaeretiella rapae": $2 \widehat{0} \& 2$ \% "60/60, Korno, B. c., 23.V.1960, *Coloradoa achilleae, Achillea millefolium, *Aphidius arvensis: $10^{\Uparrow}$ \& 1; “61/215, Královský Chlumec, Slov. or, 6.VI.1961, *Liosomaphis berberidis, Berberis vulgaris, *Aphidius 
hortensis": 2+; "61/246, Somotor, Slov. m., 7.VI.1961, Brevicoryne brassicae, Brassica napus, Diaeretiella rapae": $2 \widehat{\diamond} \& 3$ + ; “61/327, Piliš, Slov. N. Město, Slov. or., 9.VI.1961, Hyadaphis, Conium maculatum": 1; "61/535, Štúrovo, Slov. m., 29.VI.1961, Brevicoryne brassicae, Raphanus raphanistrum, Diaeretiella rapae": $2 \widehat{O}$ \& 3q; "61/568, Šahy, Slov. m., 30.VI.1961, Cryptomyzus ribis, Ribes rubrum": 19; "62/298, Praha, Semináŕská zahrada, B. c., VII.1962, Liosomaphis berberidis, Berberis vulgaris": 1 + ; “66/251, Benešov, nr. Semily, B. bor., VI.1966, Nasonovia, Saxifraga caespitosa decipiens, *Aphidius hieraciorum,": 19; “67/9, Lednice, M.m., 5.VI.1967, Aphis fabae, Chenopodium, *Binodoxys angelicae": 19; “69/71, Šamorín, Slov.m., 4.VI.1969, Brevicoryne brassicae, Brassica napus, Diaeretiella rapae": 4ð \& 5\%; "74/340, Obrátice, B.m., 28.VII.1974, Brevicoryne brassicae, Sinapis arvensis, Diaeretiella rapae": $4 \widehat{\nearrow}$ \& 19; "76/199, Průhonice, B.c., 12.VII.1976, * Therioaphis trifolii, Medicago, *Praon exsoletum": $3 \bigcirc$; "83/10, České Budějovice, B.m., 7.VI.1983, Liosomaphis berberidis, Berberis, Aphidius hortensis": 2q; "83/30, České Budějovice, B.m., 24.VI.1983, Cryptomyzus, Ribes rubrum, *Aphidius ribis": 4ð \& 4; "83/39, Holašovice, B.m., 4.VII.1983, Brevicoryne brassicae, Brassica napus, Diaeretiella rapae": $10^{\wedge}$ \& 9웅 "89/22, České Budějovice, B.m., 26.V.1989, Aphis fabae, Philadelphus coronarius, Aphidius sp.”: 1q; “60/70, Srbsko, B.c., 23.V.1960, Cryptomyzus ribis, Ribes rubrum, Aphidius ribis": $6{ }^{\lambda}$ \& 3우 "61/9, Karlštejn, B.c., 30.IV.1961, Aphis fabae, Euonymus europaeus": 19; "89/71, Veselí n.L., B.m., 10.VI.1989, Brevicoryne brassicae, Brassica napus": 1 ^ \& 5 ․ $5 \hat{\jmath} \& 5$ \% in UB.

Distribution. Cosmopolitan (Ferrer-Suay et al. 2012a). New records for the Czech and Slovak Republics.

\subsection{Alloxysta fracticornis (Thomson, 1862)}

Diagnosis. Alloxysta fracticornis is mainly characterized by having a closed radial cell 2.2 times as long as wide (Fig. 3h), pronotal carinae absent, propodeal carinae present, male and female with the beginning of rhinaria in F3, F1-F3 subequal in length (Fig. 1i), F3 curved in male. It is similar to Alloxysta mullensis (Cameron, 1883) but can be differentiated by the relation between F1 and the pedicel: F1 longer than pedicel in $A$. fracticornis (Fig. 1i) while F1 subequal to pedicel in A. mullensis (Fig. 1t); F1-F3 subequal in length in A. fracticornis (Fig. 1i) but $\mathrm{F} 1$ longer than $\mathrm{F} 2$ and $\mathrm{F} 2$ subequal to $\mathrm{F} 3$ in $A$. mullensis (Fig. 1t); F3 curved in A. fracticornis male but without any flagellomere curved in $A$. mullensis male.

Material studied. 2へ. "61/398, Plešivec, Slov. m., 13.VI.1961, *Acyrthosiphon, Euphorbia cyparissias, *Aphidius urticae": $2 \hat{\jmath} .10$ in UB.

Distribution. Palaearctic (Ferrer-Suay et al. 2012a). New record for the Slovak Republic.

\subsection{Alloxysta halterata (Thomson, 1862)}

Diagnosis. Alloxysta halterata is easily differentiated from the other brachypterous Alloxysta species (A. brachyptera, A. pedestris (Curtis, 1838 ) and $A$. apteroidea Hellén, 1963) by having pronotal carinae while the others do not. Females with normal sized wings are similar to $A$. victrix in that both species have a closed radial cell and propodeal carinae absent, but they can be differentiated by the size of radial cell: 2.4 times as long as wide in some $A$. halterata female but 3.0 times in Alloxysta victrix (Westwood, 1833) (Fig. 4m); and relation between F1 and F2 in females: F1 subequal to $\mathrm{F} 2$ in $A$. halterata while $\mathrm{F} 1$ longer than $\mathrm{F} 2$ in $A$. victrix (Fig. 1.bb).

Material studied. 1ठิ. "69/168, Jerichov, nr. Bánovce n.B., Slovenia occ., 28.VI.1969, *Aulacorthum langei, Pulmonaria officinalis": $1{ }^{\widehat{T}}$.

Distribution. Palaearctic (Ferrer-Suay et al. 2012a). New record for Slovenia.

\subsection{Alloxysta hendrikxi (Benoit, 1956)}

Diagnosis. Alloxysta hendrikxi is mainly characterized having a closed radial cell 2.2 times as long as wide (Fig. 3i), pronotal carinae absent, propodeal carinae present being thin and straight on top, forming a plate on bottom with sides angled, rhinaria and antennal club beginning in F3, F1 longer than pedicel and F2, F2 subequal to F3 
and F3 shorter than F4 (Fig. 1k). It is similar to Alloxysta mullensis but can be differentiated by the relation between $F 1$ and the pedicel: $F 1$ longer than pedicel in $A$. hendrikxi (Fig. 1k) but subequal in A. mullensis (Fig. 1t); shape of propodeal carinae: being thin and straight on top, forming a plate on bottom with sides angled in $A$. hendrikxi while forming a complete plate with curved sides in A. mullensis.

Material studied. 2 9. "89/39, C. Budejovice, B.m., 1.VI.1989, *Aphis fabae, Philadelphus coronarius": 1\%; "89/45, Nove Hrady, B.m., 5.VI.1989, Aphis fabae, A. poterii, Umbelliferae": 19.19 in UB.

Distribution. Africa (Ferrer-Suay et al. 2012a). New record for the European continent.

\subsection{Alloxysta kovilovica Ferrer-Suay \& Pujade-Villar, 2013}

Diagnosis. Alloxysta kovilovica is mainly characterized by having a closed radial cell 2.5 times as long as wide (Fig. 3j), beginning of antennal club and rhinaria in F3, F1 longer than pedicel and F2, F2 equal to F3 and F3 slightly shorter than F4 (Fig. 3j), pronotal and propodeal carinae are absent. It is similar to Alloxysta aperta (Hartig, 1841) but can be differentiated by the relation between F1-F3: not subequal in A. kovilovica while they are subequal in $A$. aperta.

Material studied. 1ㅇ. “61/617, Dolní Věstonice, M. m., 3.VII.1961, *Brachycaudus helichrysi, Matricaria inodora": 1 ㅇ.

Distribution. Serbia (Ferrer-Suay et al. 2013e: 256). New record for the Czech Republic.

\subsection{Alloxysta leunisii (Hartig, 1841)}

Diagnosis. Alloxysta leunisii is mainly characterized by having a closed radial cell, 2.0 times as long as wide (Fig. 3k), pronotal carinae present, propodeal carinae absent, rhinaria and antennal club beginning in F2, F1 longer than pedicel and subequal to F2 and F3 in female (Fig. 1m), male with the same proportions except F3 longer than F2. It is similar to A. consobrina but can be differentiated by the beginning of rhinaria in female: $\mathrm{F} 2$ in $A$. leunisii (Fig. $1 \mathrm{~m}$ ) and $\mathrm{F} 3 / \mathrm{F} 4$ in $A$. consobrina (Fig. 1h); shape of flagellomeres in male: F1 slightly curved in A. leunisii while F1-
F3 strongly curved in A. consobrina; size of radial cell: 2.0 times as long as wide in $A$. leunisii (Fig. 3k) but 2.7 times as long as wide in $A$. consobrina (Fig. 3g).

Material studied. 3․ “60/357, Stěhelčeves B. c., 17.VI.1960, *Brevicoryne brassicae, Brassica napus": 2+; "60/36, Rajhrad, M. m., 19.V.1960, Brevicoryne brassicae, Brassica napus, *Diaeretiella rapae": 19.19 in UB.

Distribution. Palaearctic (Ferrer-Suay et al. 2012a). New record for the Czech Republic.

\subsection{Alloxysta macrophadna (Hartig, 1841)}

Diagnosis. Alloxysta macrophadna is mainly characterized by having a big, partially open radial cell (Fig. 31), pronotal carinae present, propodeal carinae absent, rhinaria and antennal club beginning in F4 in females and F3 in males. It is similar to Alloxysta obscurata (Hartig, 1840) but can be differentiated by the shape and proportion between flagellomeres: F1 subequal to F2, $\mathrm{F} 2$ longer than F3 and F3 subequal to F4 in $A$. macrophadna (Fig. 1n) while F1 longer than F2, $\mathrm{F} 2$ shorter than $\mathrm{F} 3$ and $\mathrm{F} 3$ shorter than $\mathrm{F} 4$ in $A$. obscurata (Fig. 1v); F2 and F3 strongly curved in A. macrophadna male but without any flagellomere curved in A. obscurata male; size of radial cell: 3.0 times as long as wide in A. macrophadna (Fig. 31) but 2.7 times as long as wide in $A$. obscurata (Fig. 4b).

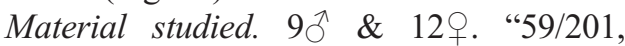
Katovice, B. occ., 25.VI.1959, *Macrosiphum rosae, Rosa, *Praon volucre": 39; "59/204, Rojice, B.m., 25.VI.1959, Macrosiphum rosae, Rosa, *Aphidius rosae": 1ठ; "59/362, Bechyně, B.m., 24.VII.1959, Acyrthosiphum pisum, Trifolium, Aphidius ervi”: 10; “60/306, Rusava, M. or., 11.VI.1960, *Macrosiphum funestum, Rubus, *Aphidius urticae": 4q; "61/387, Domica, Slov. m., 12.VI.1961, Dysaphis, Pyrus communis, *Ephedrus persicae": 20̂; "61/410, Praha, Seminářská zahrada, B. c., 20.VI.1961, *Macrosiphum gei, Geum": *Macrosiphum daphnidis, Daphne mezereum": 2q; "64/16, Slapy, B. c., 24.V.1964, Euceraphis, Betula pendula": 20̄; "64/27, Pavlovské kopce, M. m., 27.V.1964, Judenkoa, Lonicera, *Ephedrus plagiator": 1ठ;; "64/81, Prachov, B. or., VI.1964, Amphorophora ampullata, Aulacorthum 
dryopteridis, Athyrium filis-mas, Aphidius urticae": 1; "70/185, V.Tatry, Tomanova dolina, Slov.bor., 25.VII.1970, Macrosiphum, Rosa alpina": 1ð \& 1; "61/180, Královský Chlmec, S.or., 5.VI.1961, *Uroleucon aeneus, Carduus nutans": $1 \sigma^{\top} .1 \sigma^{\Uparrow} \& 3$ in UB.

Distribution. Holarctic (Ferrer-Suay et al. 2012a). New records for the Czech Republic, Poland and the Slovak Republic.

\subsection{Alloxysta melanogaster (Hartig, 1840)}

Diagnosis. Alloxysta melanogaster is mainly characterized by having a partially open radial cell 2.3 times as long as wide (Fig. $3 \mathrm{~m}$ ), pronotal and propodeal carinae present, female antennae with the beginning of rhinaria in F3, F1 subequal to pedicel, F1 longer than F2, F2 subequal to F3, F4 longer than F3 (Fig. 1o), male antennae with the beginning of rhinaria in F2, F1 longer than pedicel and F2, F2-F4 subequal in length. It is similar to A. longipennis but can be differentiated by the proportions among flagellomeres in female: pedicel-F3 in A. melanogaster while $\mathrm{F} 1$ longer than pedicel and F2, F2 subequal to F3 in A. longipennis; size of radial cell 2.3 times as long as wide in $A$. melanogaster but 2.6 times as long as wide in A. longipennnis.

Material studied. $3{ }^{\Uparrow} \&$ \& 6 . " $59 / 110$, Praha, BZKU, B.c., 9.VI.1959, *Myzus cerasi, Prunus avium, *Ephedrus cerasicola, *Ephedrus persicae, *Ephedrus plagiator": $3 q$; “60/313, Hostýn, Hostýnske hory, Mor. or., 11.VI.1960, Rhopalosiphoninus, Oxalis, *Ephedrus lacertosus": 3 त \& 2ᄋ; "66/249, Kozly, Louny, B. c., 19.VIII.1966, *Amphorophora, Pulmonaria officinalis": 1 ․ $10^{\Uparrow} \& 1$ in UB.

Distribution. Palaearctic and Oriental Regions (Ferrer-Suay et al. 2012a). New record for the Czech Republic.

\subsection{Alloxysta mullensis (Cameron, 1883)}

Diagnosis. Alloxysta mullensis is mainly characterized by having a closed radial cell 2.2 times as long as wide (Fig. 3n), pronotal carinae absent, propodeal carinae present forming a plate, beginning of rhinaria in F4, F1 longer than F2, F2 subequal to F3, F3 shorter than F4 (Fig. 1p). It is similar to A. fracticornis but can be differentiated by the relation between $\mathrm{F} 1$ and pedicel: $\mathrm{F} 1$ subequal to pedicel in A. mullensis (Fig. 1p) while F1 longer than pedicel in A. fracticornis (Fig. 1i); proportion between flagellomeres: F1 longer than F2 and F2 subequal to F3 in A. mullensis female (Fig. 1p) but F1-F3 subequal in length in $A$. fracticornis female (Fig. 1i); without any flagellomere curved in A. mullensis male but F3 curved in $A$. fracticornis male.

Material studied. 23ð \& 75․ "57/204, Praha, Kinského sady, B.c., 16.VI.1957, Aphis fabae, Philadelphus": 2ᄋ; “57/96, Praha, BZKU, B.c., 3.VI.1957, Aphis fabae, Euonymus europaeus": 1 ठ \& 2q; "58/154, Praha, Kinského sady, B.c., 2.VII.1958, *Aphis, Spirea, *Binodoxys angelicae, *Ephedrus plagiator": 1; " "58/21, Filákovo, Slov.m. 22.V.1958, *Aphis sambuci, Sambucus nigra": 1 ; " "58/231, Praha, BZKU, B,.c., 28.VII.1958, *Aphis craccivora, Robinia pseudoacacia, *Ephedrus plagiator": 19; "59/112, Praha, BZKU, B.c., 9.VI.1959, *Aphis viburni, Viburnum opulus, Binodoxys angelicae": 19.; "59/249, Praha, BZKU, B.c., 1.VII.1959, *Aphis farinosa, Salix, *Lysiphlebus cardui”: 3 ^ \& 69; “59/250, Praha, BZKU, B.c., 1.71959, Aphis fabae, Campanula rapunculoides, *Lysiphlebus cardui": $10^{\uparrow} \& 2$; "60/171, Adamov, Mor. m., 3.VI.1960, Aphis fabae, Rumex, Lysiphlebus fabarum": $19 ; 4{ }^{\Uparrow} \&$ 4; "60/336, Bot. Praha, BZKU,15.VI.1960, Aphis farinosa, Salix, Binodoxys angelicae, Lysiphlebus cardui”: 10;; “60/338, Praha, BZKU, 15.VI.1960, Aphis fabae, Arctium, Binodoxys angelicae, Lysiphlebus fabarum": $3 \circ$; "60/420, Praha, BZKU, B. c., 29.VI.1960, Aphis fabae, Beta vulgaris, Lysiphlebus fabarum": $3 \circ$; "60/442, Praha, BZKU, B. c., 6.VII.1960, Aphis farinosa, Salix, Lysiphlebus cardui": 3; "60/494. Praha,BZKU, B. c., 16.VII.1960, Aphis, Arnica sacchaliensis": 1\%; "60/502, Praha, BZKU, B. c., 16.VII.1960, Aphis, Tropaeolum majus, Binodoxys angelicae": 2+; "60/505, Praha, BZKU, B. c., 16.VII.1960, Aphis, Rumex balcanicus, Praon abjectum": 1; “60/507, Praha, BZKU, B.c, 16.VII.1960, Aphis, Rumex salicifolius": 10 \& 1\%; "60/514, Praha, BZKU, B. c., 20.VII.1960, Aphis fabae, Beta vulgaris": 19; “60/543, Trněný Újezd, B. c., 26.VII.1960, Aphis fabae, Beta vulgaris, Lysiphlebus gr.fabarum”: 19; “60/546, Trněný Újezd, B. c., 
26.VII. 1960,Thelaxes, Quercus": $2 \hat{0}$ \& 3 \% ; “60/587, Praha, BZKU, B. c., 30.VII.1960, Aphis farinosa, Salix, Lysiphlebus cardui”: 3 ㅇ; “60/84, Karlštejn, B. c., 23.V.1960, Sipha, Agropyrum”: 4+; "61/416, Praha, Seminářská zahrada, B. c., 20.VI.1961, Aphis, Spirea”: 2o; "61/428, Praha, BZKU, B. c., 21.VI.1961, Aphis pomi, Crataegus monogyna, Ephedrus plagiator": 30 त \& 6 ㅇ; “61/501, Štúrovo, Slov. m., 27.VI.1961, Sipha, Agropyrum repens, *Adialytus": 1\%; "70/209, Jičín, B. or., 20.VIII.1970, Aphis fabae, Yucca, Lysiphlebus fabarum": 1\%; "70/71, Praha, BZKU, B. c., 4.VI.1970, *Aphis frangulae, Frangula alnus, Binodoxys angelicae": 2\%; "71/139, Praha, BZKU B. c., 16.VII.1971, *Aphis pomi, Malus": 2ð \& 2ᄋ; "74/108, Praha, BZKU, B.c., 4.VI.1974, Aphis fabae, Evonymus europaeus, Praon abjectum": 1ð’; "74/118, Praha, Seminářská zahrada, B.c., 7.VI.1974, Aphis, Laburnum anagyroides, Binodoxys

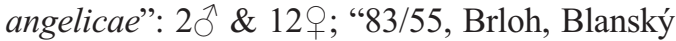
les, B.m., 14.VII.1983, Aphis jacobaeae, Senecio, *Lipolexis gracilis": 29; "60/422, Praha, BZKU, B.c., 28.VI.1960, Aphis urticata, Urtica urens": $2 \hat{\jmath} .5 \hat{\jmath} \& 5 \bigcirc$ in UB.

Distribution. Palaearctic, Neotropical and Africa Regions (Ferrer-Suay et al. 2012a). New record for the Czech and Slovak Republics.

\subsection{Alloxysta nigricans Hellén, 1963}

Diagnosis. Alloxysta nigricans is mainly characterized by having a closed radial cell 2.7 times as long as wide (Fig. 4a), pronotal carinae present, propodeal plate present, rhinaria and club shaped begin in F4 in both male and female and F1 longer than pedicel (Fig. 1q). Alloxysta nigricans is similar to $A$. antananarivoi Ferrer-Suay \& PujadeVillar, 2012, but they can be distinguished by the size of radial cell: 2.7 times as long as wide in $A$. nigricans but 2.4 times as long as wide in $A$. antananarivoi; shape of propodeal carinae: propodeal carinae forming a complete plate with few setae on top and with divergent peaks in the base in A. nigricans while propodeal carinae well defined, separed by setae in the first half and forming a plate in the last half, straight sides in $A$. antananarivoi.

Material studied. 29. "69/220, Praha, Strahovská zahrada, B. c., 20.VII.1969, Peri- phyllus, Acer platanoides, *Euaphidius setiger": 2 . 19 in UB.

Distribution. Finland (Hellén 1963: 16). New record for the Czech Republic.

\subsection{Alloxysta obscurata (Hartig, 1840)}

Diagnosis. Alloxysta obscurata is mainly characterized by having a partially open radial cell 2.7 times as long as wide (Fig. 4b), pronotal carinae present, propodeal carinae absent, female antennae with the beginning of rhinaria in F3, F1 longer than pedicel and F2, F2 subequal to F3, F3 shorter than F4 (Fig. 1r), male antennae with the beginning of rhinaria in F4, F2 slightly curved, F1 longer than pedicel and F2, F2 longer than F3 and $\mathrm{F} 3$ longer than F4. It is similar to A. macrophadna but can be differentiated by the shape and proportions among flagellomeres: F1 longer than F2, F2 shorter than $\mathrm{F} 3$ and $\mathrm{F} 3$ shorter than $\mathrm{F} 4$ in $A$. obscurata (Fig. 1r) while F1 subequal to F2, F2 longer than $\mathrm{F} 3$ and $\mathrm{F} 3$ subequal to $\mathrm{F} 4$ in $A$. macrophadna (Fig. 1n); without any flagellomere curved in $A$. obscurata male but F2 and F3 strongly curved in $A$. macrophadna male; size of radial cell: 2.7 times as long as wide in $A$. obscurata (Fig. 4b) but 3.0 times as long as wide in A. macrophadna (Fig. 3o).

Material studied. 3ત \& 19. " $58 / 255$, Karlštejn, B.c., 2.VIII.1958, Aulacorthum sp., Geranium robertianum": 1 §`; "58/315, Malackyokolí, Slov. occ., 10.IX.1958, *Myzus galeopsidis, Galeopsis speciosa, *Aphidius ribis": 1; “58/322, Hrádek, Orl. Hory, B.or., 9.X.1958, Aulacorthum, Athyrium filis-mas, *Aphidius urticae": 10;; "60/107, Karštejn, B.c., 27.V.1960, Linosiphon, Galium silvaticum": $1 \delta^{\lambda} .10$ in UB.

Distribution. Holarctic and Neotropical (Ferrer-Suay et al. 2012a). New records for the Czech and Slovak Republics.

\subsection{Alloxysta pallidicornis (Curtis, 1838)}

Diagnosis. Alloxysta pallidicornis is easily differentiated from the other Alloxysta species by its combination of features: radial cell completely open (Fig. 4c), pronotal carinae present, propodeal carinae present, well defined and separated by setae in the first half and forming a plate in the last half, beginning of rhinaria in $\mathrm{F} 2$ and $\mathrm{F} 1$ 
with very large length/width relation (Fig. 1s). It is similar to Alloxysta abdera Fergusson, 1986, but can be differentiated by the relation between F2-F4: F2-F4 subequal in length in $A$. pallidicornis but $\mathrm{F} 2$ longer than $\mathrm{F} 3$ and $\mathrm{F} 3$ longer than F4 in A. abdera; shape of propodeal carinae: propodeum with two carinae well defined and separated in the first half with setae present in $A$. pallidicornis while propodeum has two carinae joining forming a thick plate, with setae on top and curved sides in A. abdera, and they also differ in the size of radial cell: 2.6 times as long as wide in A. pallidicornis but 2.2 times as long as wide in A. abdera.

Material studied. 5․ " $59 / 202$, Katovice, B. occ., 25.VI.1959, Cinara, Pinus, *Pauesia laricis, *Pauesia pini”: 19; “59/329, Pěkná, Šumava, B.m., 22.VII.1959, Cinara, Pinus": 19; "59/335, Blažejovice, Šumava, B.m., 22.VII. 1959, Cinara, Pinus, Pauesia pini”: 1 +; “60/220, Mohelno M. m., 5.VI.1960, Cinara, Pinus sylvestris, Pauesia pini”: 1; “60/453, Vel. Tisý, B. m., 11.VII.1960, Cinara, Schizolachnus, Pinus sylvestris": 19.19 in UB.

Distribution. Holarctic (Ferrer-Suay et al. 2012a). New records for Poland and the Czech Republic.

\subsection{Alloxysta pilipennis (Hartig, 1840)}

Diagnosis. Alloxysta pilipennis is mainly characterized by having a closed radial cell 2.5 times as long as wide (Fig. 4d), pronotal and propodeal carinae present, female antennae with the beginning of rhinaria in F3, F1 longer than pedicel and F2, F2-F4 subequal in length (Fig. 1t). It is similar to Alloxysta pusilla (Kieffer, 1902) but can be differentiated by the proportions among flagellomeres: $\mathrm{F} 2$ subequal to $\mathrm{F} 3$ in $A$. pilipennis female (Fig. 1t) but F2 shorter than F3 in $A$. pusilla female (Fig. 1 $\mu$.); F1-F3 not subequal and without any flagellomere curved in A. pilipennis male but F1-F3 subequal in length and slightly curved in A. pusilla male; size of radial cell: 2.4 times as long as wide in $A$. pilipennis female (Fig. 4d) but 2.7 times as long as wide in A pusilla female (Fig. 4h).

Material studied. 21ठ \& 50․ "58/238, Karlštejn, B.c. 2.VIII.1958, *Macrosiphum rosae, Rosa": 1; "59/243, Praha, Strahovská zahrada, B.c., 28.VI.1959, M. only, Acer platanoides" : 2+; "59/95, Zadní Třebaň, B.c., 29.V.1959, Eucallipterus, Tilia, *Trioxys curvicaudus": 29; "60/333, Praha, Strahovska zahrada, B.c., 12.VI.1960, Dysaphis, Malus communis": 1q; “60/343, Raná, Louny, B. c., 17.VI.1960, Sappaphis ?, Pyrus communis, *Ephedrus persicae": 2ᄋ; "60/346, Raná, Louny, B. c., 17.VI.1960, Dysaphis, Malus communis, Ephedrus persicae": 19.; "60/365, Praha, Kinského sady, B. c., 21.VI.1960, Drepanosiphum, Acer pseudoplatanus, *Dyscritulus planiceps": 1\%; “61/161, Královský Chlmec, Slov. or, 5.VI.1961, Myzus cerasi, Prunus avium, *Ephedrus cerasicola, Ephedrus persicae": 2今; "61/35, Český Krumlov, B. m., 10.V.1961, Aphis fabae, Euonymus europaeus, *Ephedrus plagiator": 19; "61/454, Karlštejn, B. c., 23.VI.1961, Macrosiphoniella oblonga, Artemisia vulgaris, *Aphidius phalangomyzi": 19; "62/339, Praha, M. Strana, B. c., VII.1962, *Aphis pomi, Ovatus, Crataegus, Binodoxys angelicae": 1; “"62/36, Lovoš, Č. Středohoří, B. bor., 31.V.1962, Myzus cerasi, Prunus avium, Ephedrus persicae": 2へ \& 1\%; “64/27, Pavlovské kopce, M. m., 27.V.1964, Judenkoa, Lonicera, Ephedrus plagiator": 1\%; "64/65, Praha, Kinského sady, B.c., 8.VI.1964, Periphyllus, Acer platanoides": 1\%; "66/71, Lednice, M. m., 11.V.1966, *Phorodon humuli, Prunus domestica, Ephedrus persicae, Ephedrus plagiator, *Praon volucre": 20̄; "66/94, Lednice, M. m., 24.V.1966, Phorodon humuli, over all outbreak, Prunus domestica, Ephedrus plagiator, Praon volucre": 1ठ; "68/342, Těchobuz, B. m., 25.VII.1968, *Aphis fabae, Cirsium arvense, *Lysiphlebus fabarum.": 1\%; “68/369, Praha, Seminářská zahrada, B. c., 12.VIII.1968, *Drepanosiphum platanoides, Acer pseudoplatanus": 2ᄋ; "69/105, Praha, Kinského sady, B. c., 17.VI.1969, Periphyllus, Acer platanoides, *Euaphidius setiger, Trioxys falcatus": 19; "69/14, Praha, Seminářská zahrada, B. c., 16.V.1969, *Periphyllus testudinaceus, Acer pseudoplatanus": 10 \& \& 3; “69/17, Praha, Seminářská zahrada, B. c., 16.V.1969, Periphyllus testudinaceus, Acer campestre": 1; “69/170, Praha, Nábřeží Legií, B.c., 22.VI.1969, Periphyllus, Acer platanoides, *Falciconus pseudoplatani”: 19; “69/180, 
Červený Kláštor, Pierniny, Slov.bor., 1.VII.1969, Periphyllus sp., Periphyllus lyropictus, Acer platanoides, Euaphidius setiger": 1; "69/181, Praha, Seminářská zahrada, B.c., 1.VII.1969, *Periphyllus lyropictus, Acer platanoides, Euaphidius setiger": 1ㅇ; "69/183, Praha, Seminářská zahrada, B.c., 1.VII.1969, Periphyllus, Acer platanoides" : 1 ; "69/216, Praha, Seminářská zahrada, B. c., 20.VII.1969, Periphyllus, Acer platanoides, Euaphidius setiger": 10ิ; "69/220, Praha, Strahovská zahrada, B. c., 20.VII.1969, Periphyllus, Acer platanoides, Euaphidius setiger”: 2o; “69/246, Praha, B. c., 23.X.1969, Myzus varians, Clematis alba, Ephedrus plagiator": 19; “69/26, Praha, Seminářská zahrada B. c., 23.V.1969, Drepanosiphum, Acer pseudoplatanus": 4ㅇ; “69/30, Praha, Seminářská zahrada, B. c., 23.V.1969, Drepanosiphum, Acer pseudoplatanus": 20⿱ \& 19; "69/39, Praha, Seminářská zahrada, B. c., 23.V.1969, Periphyllus, Acer campestre, *Areopraon silvestre": 20; "70/130, Lednice, M. m., 19.VI.1970, Periphyllus rhenanus, Acer platanoides": 1q; "70/14, Valtice, M. m., 7.V.1970, Periphyllus sp., Periphyllus hirticornis, Acer campestre": 10 \& 1ㅇ; "70/22, Valtice, M. m., 27.V.1970, Drepanosiphum, Acer pseudoplatanus, Falciconus pseudoplatani, *Trioxys cirsii": 10 \& 1 1 +; "70/32, Valtice, M. m., 27.V.1970, Periphyllus lyropictus, Acer platanoides, Areopraon silvestre, Trioxys falcatus": 1q; "70/64, Bystřice p.Host., M. or., 29.V.1970, Periphyllus aceris, Acer platanoides, Areopraon silvestre": 10 \& 2ᄋ; "70/84, Praha, BZKU, B. c., 4.VI.1970, Periphyllus testudinaceus, Acer platanoides, Areopraon silvestre": $10^{\widehat{A}} \& 1$ \% ; "70/88, Praha, BZKU, B. c., 4.VI.1970, Periphyllus, Acer pseudoplatanus, Trioxys falcatus": $1 \delta^{\widehat{\alpha}}$ \& 2ᄋ; "71/102, Praha, Strahov, B.c., 20.VI.1971, Dysaphis plantaginea, Malus, Ephedrus persicae": 1; "71/38, Praha, Kinského sady, B. c., 27.V.1971, Dysaphis, Malus communis, Ephedrus persicae": 1\%; "71/43, Praha, Šárka, B c, 30.V.1971, Dysaphis, Malus communis, *Ephedrus dysaphidis": 10̂; "74/295, Praha, Seminářská zahrada, B.c., 10.VII.1974, Drepanosiphum, Acer pseudoplatanus, Dyscritulus planiceps, *Falciconus pseudoplatani”:
1ㅇ; "89/117, České Budějovice, B.m, 15.VI.1989, *Cryptomyzus ribis, Ribes rubrum": 1ㅇ; "61/680, Praha, Kinského sady, B.c., 10.VII.1961, Acyrthosiphon caraganae, Caragana arborescens": 1; "70/64a, Bystřice p.Host., M.or., 29.V.1970, Periphyllus aceris et spp., Acer platanoides": $20^{\lambda} .5{ }^{\lambda} \& 5$ in UB.

Distribution. Palaearctic and Neotropical (Ferrer-Suay et al. 2012a). New records for the Czech and Slovak Republics.

\subsection{Alloxysta pilosa}

Ferrer-Suay \& Pujade-Villar, 2013

Diagnosis. Alloxysta pilosa is mainly characterized having an open radial cell, 4.9 times as long as wide (Fig. 4e), female antennae with the beginning of rhinaria in $\mathrm{F} 4$ in female and $\mathrm{F} 3$ in male, $\mathrm{F} 1$ subequal to pedicel and slightly shorter than F2, F2 subequal to F3 in female (Fig. 1u), F1 longer than pedicel and subequal to F2, F2 shorter than F3 in male, pronotal carinae present and propodeal carinae absent. It is similar to Alloxysta brachycera Hellén, 1963, but can be differentiated by pilosity of body: body covered by abundant pubescence in A. pilosa but only by scattered setae in A. brachycera; size of radial cell: 4.9 times as long as wide in A. pilosa, 2.7 times as long as wide in $A$. brachycera.

Material studied. 19. "69/172, Těchobuz, nr. Pacov, B.m., 21.VI.1969, *Impatientinum balsamines, Impatiens noli tangere, *Monoctonus nervosus": 19 in UB.

Distribution. Eastern Palaearctic: Japan. Oriental Region: Nepal, Thailand and Taiwan (Ferrer-Suay et al. 2013e). New record for central Europe.

\subsection{Alloxysta pleuralis (Cameron, 1879)}

Diagnosis. This species is easily differentiated from other Alloxysta species by the following combination of features: partially open radial cell (Fig. 4f); pronotal carinae present; two well defined propodeal carinae reaching the base independenty; female antennae: F1 longer than F2, F2 shorter than F3 and F3 shorter than F4 (Fig. 1v); male antennae: F1-F3 subequal in length and slightly curved. It is similar to Alloxysta citripes (Thomson, 1862) but can be 
easily differentiated by the shape of propodeal carinae: propodeum with two carinae well defined, reaching the base independently, thick and with the sides curved in A. pleuralis while in $A$. citripes propodeal carinae are not protruding.

Material studied. $17 \hat{\delta} \& 123$ \& . "57/204, Praha, Kinského sady, B.c., 16.VI.1957, Aphis fabae, Philadelphus": 19; "58/116, Praha, Seminářská zahrada, B.c., 8.VI.1958, *Aphis, Spirea": 1 9 ; "58/174, Synkov, B. or. 7.VII.1958, *Cavariella, *Heracleum, *Ephedrus helleni": 3 ; ; "58/228, Komárov, B. or., 23.VII.1958, *Aphis cognatella, Euonymus europaeus, *Binodoxys angelicae": 19; "58/282, Těchobuz, nr. Pacov, B.m. 20.VIII.1958, Aphis, Vicia, *Binodoxys acalephae": 39; "59/112, Praha, BZKU, B.c., 9.VI.1959, *Aphis viburni, Viburnum opulus, Binodoxys angelicae": 19; "59/116, Praha, BZKU, B.c., 9.VI.1959, Aphis pomi, Malus communis, Binodoxys angelicae": 1\%; "59/116, Praha, BZKU, B.c., 9.VI.1959, Aphis pomi, Malus communis, Binodoxys angelicae": 3; "59/291, Mnichová, Orl.hory, B. or., 8.VII.1959, Cavariella sp., Salix, *Aphidius salicis”: 19; “59/368, Praha, Seminářská zahrada, B. c., 18.VII.1959, Aphis, Robinia, *Praon abjectum": 1; "60/141, Král.Chlmec, Slov. or., 1.VI.1960, Aphis urticata, Urtica dioica, Binodoxys acalephae": 29; "60/212, Uherčice, M.m., 4.VI.1960, *Aphis salviae, Salvia nemorosa, Binodoxys acalephae, *Lipolexis gracilis": 5q; “60/320, Praha, Seminářská zahrada, B.c., 12.VI.1960, *Aphis urticata, Urtica dioica, Binodoxys acalephae": $10^{\top} \& 1$ \% "60/338, Praha, BZKU, 15.VI.1960, Aphis fabae, Arctium, Binodoxys angelicae, Lysiphlebus fabarum": 10 \& 5; "60/400, Praha, BZKU, B. c., 25.VI.1960, Aphis fabae, Cirsium, Carduus rigens, Praon abjectum": 1\%; "60/405, Praha, BZKU, B. c., 25.VI.1960, Aphis farinosa, Salix repens rosmarinifolia, Binodoxys angelicae, *Lysiphlebus cardui”: 2q; “60/440, Mnich. Hradiště, B.sept., 1.VII.1960, Aphis fabae, Beta vulgaris": 5+; "60/442, Praha, BZKU, B. c., 6.VII.1960, *Aphis farinosa, Salix, Binodoxys

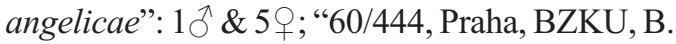
c., 7.VII.1960, Aphis pomi, Malus sylvestris, Binodoxys angelicae": 11q; "60/507, Praha, BZKU, B. c., 16.VII.1960, Aphis, Rumex salicifolius": 19; "60/540, Karlík, B. c.,
26.VII.1960, Angelica": 1+; “60/545, Trněný Újezd, B. c., 26.VII.1960, Aphis pomi, Malus sylvestris, Binodoxys angelicae": 7우 "60/586, Praha, BZKU, B. c., 30.VII.1960, Aphis, Robinia pseudoacacia, Binodoxys angelicae, Lysiphebus cardui": 6; "60/607, Těchobuz, nr.Pacov, B. m., Aphis craccae, Vicia cracca, *Lysiphlebus fritzmuelleri”: 3 우 “61/161, Královský Chlmec, Slov. or, 5.VI.1961, *Myzus cerasi, Prunus avium, *Ephedrus cerasicola, *Ephedrus persicae": 1q; "61/346, Piliš, Slov. N. Město, Slov. or., 9.VI.1961, *Aphis mordwilkiana, Rubus": 19; "61/416, Praha, Seminářská zahrada, B. c., 20.VI.1961, Aphis, Spirea": 1\%; "61/522, Štúrovo, Slov. m., 28.VI.1961, Aphis, Caragana arborescens, Binodoxys acalephae": 19; "62/339, Praha, M. Strana, B. c., VII.1962, Aphis pomi, Ovatus, Crataegus, Binodoxys angelicae": 3o; "62/367, Stranná, B. m., VII.1962, Aphis fabae, Cirsium, Lysiphlebus fabarum ": 1; "62/375, Žirovnice, B. m., VIII.1962, Aphis fabae, Cirsium”: 1 1 ; “70/163, Praha, Seminářská zahrada, B. c., 16.VII.1970, Aphis pomi, Malus communis, Binodoxys angelicae": 5; "71/101, Praha, Strahov, B.c, 20.VI.1971, Aphis pomi, Malus, Binodoxys angelicae": 2ᄋ; "71/122, Praha, BZKU, B. c,. 8.VII.1971, Dysaphis, Pyrus communis, Binodoxys angelicae, Ephedrus persicae": $3 \widehat{\delta}$ \& 1; " "71/139, Praha, BZKU, B. c., 16.VII.1971, Aphis pomi, Malus": 4; "71/67, Kroměříž M. or., 7.VI.1971, Aphis urticata, Urtica dioica, Binodoxys acalephae": 39; "72/155, Karlštejn, B. c., 7.VII.1972, Aphis pomi, Malus, Binodoxys angelicae": 3 +; "74/108, Praha, BZKU, B.c., 4.VI.1974, Aphis fabae, Evonymus europaeus, Praon abjectum": 19; "74/321, Průhonice, B.c., 13.VII.1974, Aphis pomi, Cotoneaster horizontalis, Binodoxys angelicae": $2 \widehat{\diamond} \& 1$; "74/333, Praha, BZKU, B.c., 24.VII.1974, *Aphis nasturtii, Caltha palustris, Binodoxys acalephae, Praon abjectum": 3; "78/208, Vítonice, nr. Kroměříž, M. or., 14.VII.1978, Aphis urticata, Urtica dioica, Binodoxys acalephae": 29; "80/14, Př́bram, B.c., 2.VII.1980, Aphis urticata, Urtica dioica, Binodoxys acalephae": 19; "81/35, Obrátice, B.m., 18.IX.1981, Aphis fabae, Cirsium arvense, Lysiphlebus cardui”: 7○; "83/42, České Budějovice, B.m., 4.VII.1983, Aphis fabae, 
Cirsium arvense, Lysiphlebus cardui": 7; "83/50, České Budějovice, B.m., 13.VIII.1983, Aphis fabae, Cirsium arvense": 2ᄋ; "84/141, Jetřichovec, B.m., 6.VIII.1984, Aphis fabae, Cirsium arvense, Lysiphlebus cardui": 1; "84/145, Pacov, B.m., 8.VIII.1984, Aphis fabae, Cirsium arvense": 5+; "85/22, Lednice, M.m., 3.VII.1985, Aphis urticata, Urtica dioica, Binodoxys acalephae": 69; "85/24, Lednice, M.m., 3.VII.1985, *Aphis intybi, Cichorium intybus, *Lipolexis gracilis": 69; " $85 / 25$, Lednice, M.m., 3.VII.1985, Aphis fabae, Chenopodium, Binodoxys angelicae, *Ephedrus nacheri, Ephedrus plagiator": 19 ; " $85 / 3$, České Budějovice, B.m., 17.VI.1985, Aphis craccae, Vicia cracca, Binodoxys acalephae, Praon abjectum": 1q; "85/33, Holešov, M.or., 3.VII.1985, Aphis fabae, Cirsium arvense, Binodoxys acalephae, Lysiphlebus cardui ": 10 ' \& 8; "85/36, Bílavsko, M.or., 4.VII.1985, Aphis fabae, Cirsium arvense": 4우 "85/46, Kojetín, M.c., 4.VII.1985, Aphis fabae, Artium, Binodoxys acalephae": $4 \curvearrowright$ \& 8 \% ; "85/54, Pištín, B.m., 10.VII.1985, Aphis fabae, Faba vulgaris, Binodoxys angelicae, Lysiphlebus fabarum": 10O;; "85/69, Jetřichovec, B.m., 26.VII.1985, Aphis fabae, Chenopodium, Ephedrus plagiator": 5o; "85/72, Jetřichovec, B.m., 18.VIII.1985, Aphis fabae, Chenopodium, Lysiphlebus fabarum": 20 \& 13q; "87/79, Holašovice, Záboří, B.m., 15.VII.1987, Aphis fabae cirsiiacanthidis, Cirsium arvense": 7q; "89/134, České Budějovice, B.m,.19.VI.1989, Mummies only, Malus, Binodoxys angelicae": 4; "89/155, České Budějovice, B.m, 21.VI.1989, Aphis fabae, Philadelphus, Binodoxys angelicae": 9ᄋ; "89/186, České Budějovice, B.m., 2.VII.1989, Aphis fabae, Philadelphus": 1+; "58/231b, Praha, BZKU, B.c., 25.VII.1958, Aphis craccivora, Robinia pseudoacacia": 2ᄋ; “60/360, Praha, Seminářská zahrada, B.c., 21.VI.1960, Aphis fabae, Philadelphus coronarius": 19; "60/446, Praha, Seminářská zahrada, B.c., 8.VII.1960, *Aphis spiraephaga, Spirea vanhoutei": 19; "85/27, Lednice, M.m., 3.VII.1985, Aphis fabae, Cirsium

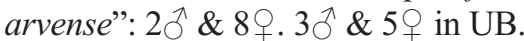

Distribution. Palaearctic and Oriental Regions (Ferrer-Suay et al. 2012a). New records for the Czech and Slovak Republics.

\subsection{Alloxysta postica (Hartig, 1841)}

Diagnosis. Male unknown. Alloxysta postica is mainly characterized by having a partially open radial cell 2.5 times as long as wide (Fig. 4g), pronotal carinae and propodeal carinae present, female antennae with the beginning of rhinaria in F4, pedicel-F4 subequal in length (Fig. 1w). It is similar to A. citripes but can be differentiated by the shape of the propodeal carinae: clearly visible and forming a protruding plate in $A$. postica while the carinae are not protruding in $A$. citripes; size of radial cell: 2.5 times as long as wide in $A$. postica (Fig. 4g) but 2.1 times as long as wide in A. citripes (Fig. 3f).

Material studied. 4․ "58/222, Žíželice, nr. Chlumec, B. or., 25.VII.1958, Cavariella sp., Angelica sylvestris, *Aphidius salicis": 39 ; "60/443, Praha, BZKU, B. c., 7.VII.1960, Brachycaudus, Prunus persica, Binodoxys angelicae, "Ephedrus persicae": 19.19 in UB.

Distribution. Palaearctic (Ferrer-Suay et al. 2012a). New record for the Czech Republic.

\subsection{Alloxysta pusilla (Kieffer, 1902)}

Diagnosis. Alloxysta pusilla is mainly characterized having a closed radial cell 2.7 times as long as wide in female (Fig. 4h) and 2.4 times as long as wide in male, pronotal and propodeal carinae present forming a plate, female antennae with the beginning of rhinaria in F3, F1 longer than pedicel and F2, F2 shorter than F3 and F3 shorter than F4 (Fig. 1x), male antennae with the beginning of rhinaria in F1, pedicel-F3 subequal in length, F4 longer than F3, F1-F3 slightly curved. It is similar to A. pilipennis but can be differentiated by the proportions between flagellomeres in both male and female: F2 shorter than F3 in $A$. pusilla female (Fig. 1x) but F2 subequal to F3 in A. pilipennis female (Fig. 1x); F1-F3 subequal in length and slightly curved in A. pusilla male but F1-F3 not subequal and without any flagellomere curved in $A$. pilipennis male; size of the radial cell: 2.7 times as long as wide in $A$. pusilla female (Fig. 4h) but 2.4 times as long as wide in $A$. pilipennis female (Fig. 4d).

Material studied. 53ㅅ \& 41․ " "58/106, Praha, Seminářská zahrada, B.c., 1.VI.1958, Par., Rosa": 1今̄; "58/110, *Rhopalomyzus alpigenae, Lonicera tatarica, Praha, BZKU, B.c., 

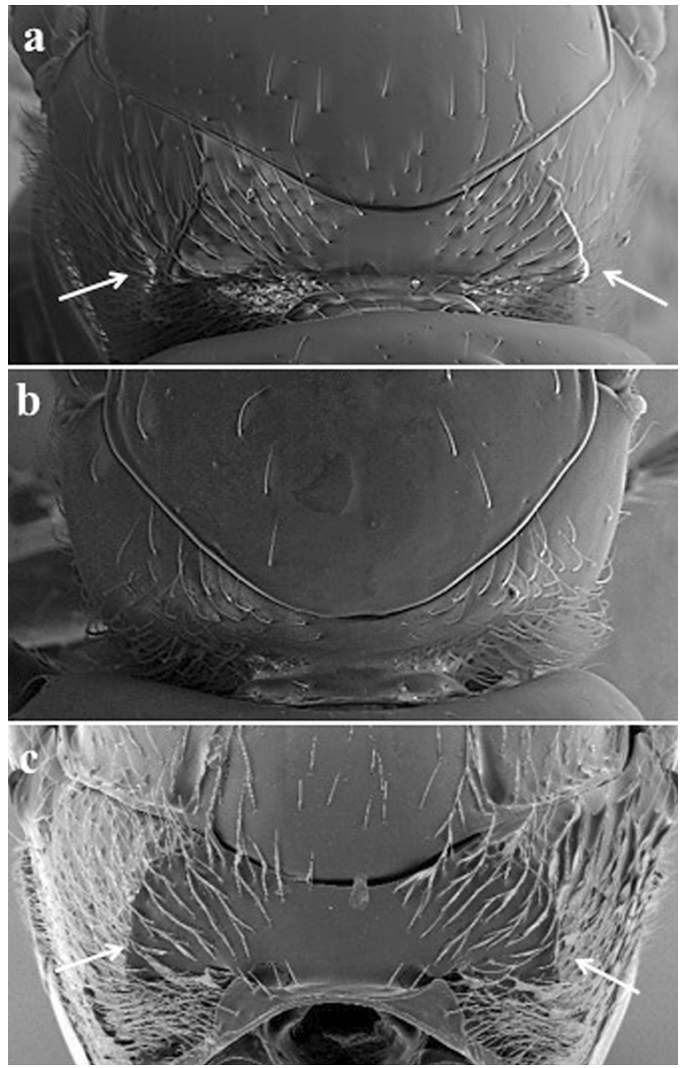

Fig. 5. Types of pronotum. - a. Alloxysta arcuata. - b. A. brevis. - c. Phaenoglyphis americana.

30.V.1958”: 1 đ \& 1; "58/234, Praha, BZKU, B. c.,31.VII.1958, Aphis fabae, Cirsium, *Lysiphlebus fabarum": 1 đ \& 4O; "58/241, Karlštejn, B.c. 2.VIII.1958, Aphis fabae, Lappa major, Lysiphlebus fabarum": 19; "58/282, Těchobuz, nr. Pacov, B.m. 20.VIII.1958, Aphis, Vicia, *Lysiphlebus fabarum": 1ठ; "59/20, Kysak, Slov. or., 23.V.1959, Aphis fabae, Euonymus europaeus, *Ephedrus plagiator": 19; "60/156, Král.Chlmec, Slov. or., 1.VI.1960, *Aphis urticata, Urtica dioica, *Binodoxys acalephae, Lysiphlebus fabarum": 2ᄋ'; “60/164, Král.Chlmec, Slov. or, 1.VI.1960, *Aphis, Onobrychis sativa, Binodoxys acalephae": $4 ð$ \& 6; “"60/212, Uherčice, M.m., 4.VI.1960, *Aphis salviae, Salvia nemorosa, Binodoxys acalephae, *Lipolexis gracilis": 5 ^’; "60/336, Praha, BZKU, B.c., 15.VI.1960, *Aphis farinosa, Salix, *Binodoxys angelicae, *Praon abjectum": 10'; “60/440, Mnich. Hradiště, B. bor., 1.VII.1960, Aphis fabae, Beta vulgaris”: 2○; “60/517, Praha,
BZKU, B. c., 20.VII.1960, Aphis urticata, Urtica urens, *Diaeretiella rapae": 2今'; "60/543, Trněný Újezd, B. c., 26.VII.1960, Aphis fabae, Beta vulgaris, Lysiphlebus fabarum": 30 \& 4 웅 “60/543, Trněný Újezd, B. c., 26.VII.1960, Aphis fabae, Beta vulgaris, Lysiphlebus fabarum": $3{ }^{\text {त }}$ \& 3; "61/183, Královský Chlumec, Slov. or, 5.VI.1961, *Aphis polygonata, Polygonum aviculare, *Lipolexis gracilis": 1ठ; "61/218, Královský Chlumec, Slov. or, 6.VI.1961, *Myzus ligustri, Ligustrum, *Monoctonus ligustri, *Praon volucre": 1†; “61/329, Piliš, Slov. N. Město, Slov. or., 9.VI.1961, Capitophorus, Carduus nutans, *Aphidius matri-

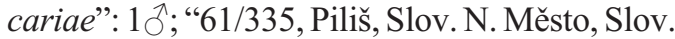
or., 9.VI.1961, *Aphis euphorbiae, Euphorbia cyparissias, Binodoxys acalephae": $4{ }^{\top}$ \& 4ㅇ; "61/606, Mikulov, Mor. m., 2.VII.1961, Aphis fabae, Beta vulgaris”: 1ठ; “61/95, Karlštejn, B. c., 19.V.1961, *Phorodon humuli, Prunus domestica": 10`; "62/365, Žirovnice, B. m., 12.VIII.1962, Cavariella, Salix": 10̄; "62/484, Těchobuz, B. m., VIII.1962, Aphis fabae, Cirsium, Lysiphlebus fabarum ": 1 1ð’; “62/528, Smilovy hory, B. m., VIII.1962, Aphis fabae, Cirsium, Lysiphlebus fabarum, ": 19; "64/63, Praha, Botanická zahrada, B.c., 6.VI.1964, Hyalopterus pruni, Prunus domestica, Ephedrus plagiator": 1; "66/100, Lednice, M. m., 24.V.1966, Aphis urticata, Urtica dioica, Lysiphlebus fabarum": 2 § 8 9 ; "83/40, České Budějovice, B.m., 4.VII.1983, Aphis fabae, Cirsium, Binodoxys acalephae, Lysiphlebus fabarum": $3{ }^{\lambda} \&$ \& 9 ; " $85 / 22$, Lednice, M.m., 3.VII.1985, Aphis urticata, Urtica dioica, Binodoxys acalephae": $2{ }^{\lambda}$ \& 19 ; " $85 / 24$, Lednice, M.m., 3.VII.1985, *Aphis intybi, Cichorium intybus, Lipolexis gracilis": 2へ; "85/54, Pištín, B.m., 10.VII.1985, Aphis fabae, Faba vulgaris, Binodoxys angelicae, Lysiphlebus fabarum": 1Ō; "87/123, Holašovice - Záboří, B.m., 19.VII.1987, Schizaphis typhaeae, Typha, Diaeretiella rapae, Ephedrus plagiator": 3 \%; "61/287, Svätuša, S.or., 8.VI.1961, Aphis fabae, Chenopodium": 1ठ; "85/27, Lednice, M.m., 3.VII.1985, Aphis fabae, Cirsium arvense": 2 ㅇ. $5 \hat{\jmath} \& 5$ in UB.

Distribution. Palaearctic and Oriental Regions (Ferrer-Suay et al. 2012a). New records for the Czech and Slovak Republics. 


\subsection{Alloxysta ramulifera (Thomson, 1862)}

Diagnosis. Alloxysta ramulifera is mainly characterized by having a small closed radial cell, 2.0 times as long as wide (Fig. 4i), pronotal carinae present but very small and sometimes difficult to see under the pubescence, propodeal carinae forming a plate, rhinaria and antennal club begin in F4, F1 subequal to pedicel, F1 longer than F2, F2 subequal to F3, F3 shorter than F4 (Fig. 1y). Alloxysta ramulifera is very similar to $A$. arcuata in that both species have pronotal carinae, a propodeal plate, and radial cell small and closed. They can be distinguished by: shape of pronotal carinae, small and sometimes very difficult to see under the pubescence in $A$. ramulifera (thick and clearly visible in A. arcuata); shape of propodeal plate, in $A$. ramulifera carinae are straight and separated by setae in the first $1 / 3$ and forming a plate in the last $2 / 3$ (forming a complete plate in $A$. arcuata); and in size of radial cell: 2.0 times as long as wide in $A$. ramulifera (Fig. 4i) (2.3 times as long as wide in $A$. arcuata Fig. 3a).

Material studied. 1ð \& 9q. "60/507, Praha, BZKU, B. c., 16.VII.1960, Aphis, Rumex salicifolius": 19; "60/523, Dobřichovice, B. c., 26.VII.1960, Aphis, Rumex, *Lysiphlebus confusus": 3 9; "60/543, Trněný Újezd, B. c., 26.VII.1960, *Aphis fabae, Beta vulgaris, Lysiphlebus confusus ": $1 \delta^{\Uparrow} \& 3 \%$; “66/100, Lednice, M. m., 24.V.1966, *Aphis urticata, Urtica dioica, Lysiphlebus confusus ": 1 ; "66/93, Lednice, M. m., 24.V.1966, *Aphis spiraephaga, Spirea, *Binodoxys angelicae": 19; "70/98, Těchobuz, nr. Pacov, B. m., 15.VI.1970, *Lipaphis erysimi, Thlaspi arvense, *Ephedrus nacheri, *Praon volucre": $1{ }^{\top} .39$ in UB.

Distribution. Palaearctic (Ferrer-Suay et al. 2012a). New record for the Czech Republic.

\subsection{Alloxysta sawoniewiczi (Kierych, 1988)}

Diagnosis. Alloxysta sawoniewiczi is similar to $A$. arcuata in having closed radial cell, pronotal and propodeal carinae, and F1 subequal to pedicel. They can be distinguished by: A. sawoniewiczi has antennae shorter than body length, while $A$. arcuata has them longer; in $A$. sawoniewiczi rhinaria begin in F5 in female (Fig. 1z) and F4 in male, in A. arcuata rhinaria begin in $\mathrm{F} 3$ in female (Fig. 1a) and F2 in male; A. sawoniewiczi has propodeal carinae narrow and well defined in upper half, wide and forming a plate in lower half with sharp margins, while $A$. arcuata has propodeal carinae forming a complete plate with few setae on top and margins slightly curved.

Material studied. 10ิ \& 2q. "57/107, Lnáře, B.m., 5.VI.1957, *Aphis farinosa, Salix, *Binodoxys angelicae": 19; "71/137, Praha, Karlovo náměstí, B. c., 13.VII.1971, Hyadaphis foeniculi, Lonicera xylosteum": $1 \overbrace{}^{\Uparrow} \& 1$ \& 1 \% in UB.

Distribution. Palaearctic (Ferrer-Suay et al. 2012a). New record for the Czech Republic.

\subsection{Alloxysta semiaperta Fergusson, 1986}

Diagnosis. Alloxysta semiaperta is mainly characterized by having a partially open radial cell, 2.7 times as long as wide (Fig. 4k), pronotal carinae present, propodeal carinae absent, rhinaria and antenal club begin in F3 in female and F4 in male; F1 longer than pedicel and F2, F2 shorter than F3 in female and subequal in male, F3 shorter than F4 (Fig. 1aa). It is similar to Alloxysta salicicola Belizin, 1973, but they can be differentiated by the length of the flagellomeres, being the realtion between lenght and width longer in A. salicicola.

Material studied. $5 \hat{\text { ๙ } \& ~ 8}$ ㅇ. "59/77, Praha, Seminářská zahrada, B.c., 24.V.1959, *Macrosiphum gei, Geum, *Aphidius urticae": 10̄; "59/80, Praha, Semináŕská zahrada, B.c., 24.V.1959, Hyperomyzus, Grossularia, *Ephedrus plagiator, *Praon volucre": 19; "60/96, Karlštejn, B. c., 23.V.1960, *Macrosiphum rosae, Rosa, *Aphidius rosae": 1ठ;; "62/15, Lovoš, Č. Středohoří, B bor., 31.V.1962, Aphidius rosae, Macrosiphum rosae, Rosa": 1 ; “67/36, Těchobuz, nr. Pacov, B. m., 7.VI.1967, *Impatientinum balsamines, Impatiens noli tangere, *Praon longicorne": 10 \& \& 1; " $69 / 54$, Karlštejn, B. c., 28.V.1969, Linosiphon, Galium silvaticum": 1\%; "70/174, Karlštejn, B. c., 22.VII.1970, *Impatientinum asiaticum, Impatiens parviflora": 2đ; "70/196, Konopiště, B. c., 2.IX.1970, Impatienttinum balsamines, Impatiens parviflora, Praon volucre": 1; "74/288, Praha, Kinského sady, B.c, 10.VII.1974, Myzocallis, Corylobium, Corylus": 
1ㅇ; “92/78, Chvalčov, nr. Bystřice pod Hostýnem, M.or., 25.VIII.1992, Impatientinum asiaticum, Impatiens parviflora": 29.19 in UB.

Distribution. Palaearctic (Ferrer-Suay et al. 2012a). New record for the Czech Republic.

\subsection{Alloxysta victrix (Westwood, 1833)}

Diagnosis. Alloxysta victrix is mainly characterized by having a large, closed radial cell 3.0 times as long as wide (Fig. 41), pronotal carinae present, propodeal carinae absent lacking setae on longitudinal areas where carinae are present in other Charipinae species (Fig. 6b), beginning of rhinaria in F3, F1 longer than pedicel and F2, F2F4 subequal (Fig. 1bb), F1-F3 curved in male. It is similar to $A$. consobrina but can be differentiated by the proportion between flagellomeres: F2-F4 subequal in length in A. victrix (Fig. 1bb) while $\mathrm{F} 2$ subequal to $\mathrm{F} 3$ and $\mathrm{F} 3$ shorter than $\mathrm{F} 4$ in A. consobrina (Fig. 1h); size of radial cell: 3.0 times as long as wide in $A$. victrix (Fig. 4l) but 2.7 times as long as wide in A. consobrina (Fig. 3g), and type of propodeal pubescence: in A. victrix propodeum lacks setae at the longitudinal area where carinae are present in Charipinae while $A$. consobrina has propodeum completely covered with dense setae.

Material studied. 81ð \& 148ㅇ. "58/132, Praha, Ruzyně, B.c. 13.VI.1958, *Cryptomyzus ribis, Ribes rubrum, *Aphidius ribis": 89 \& $2 \hat{\jmath}$; “58/228, Komárov, B. or., 23.VII.1958, *Aphis cognatella, Euonymus europaeus, *Binodoxys angelicae": 1q; "58/238, Karlštejn, B.c. 2.VIII.1958, Macrosiphum rosae, Rosa": 10َ; “58/321, Bělá p.B., N. Paka, B.c., 5.X.1958, *Amphorophora ampullata, Dryopteris austriaca": 10̄; "58/95, Pov. Inovec, Slov.occ., 30.V.1958”: 1 đ; " 58/98, Pov. Inovec, Slov. occ., 30.V.1958 Nasonovia, Silene, *Aphidius hieraciorum, *Praon pubescens": 1ठ; "59/172, Studnice, B.m., 22.VI.1959, Cavariella sp., Heracleum sphondylium": 1ठ; "59/204, Rojice, B.m., 25.VI.1959, Macrosiphum rosae, Rosa, Aphidius rosae": 2 đ \& 39; "59/209, Dubí h., Strakonice, B. occ., 25.VI.1959, Macrosiphum rosae, Rosa": 1 q; "59/282, Říčky, Orl.hory, B. or., 7.71959, *Macrosiphum prenathidis, Prenanthes purpurea, Praon volucre": 1 \%; "59/282, Říčky, Orl.hory, B. or., 7.VII.1959, Macro-

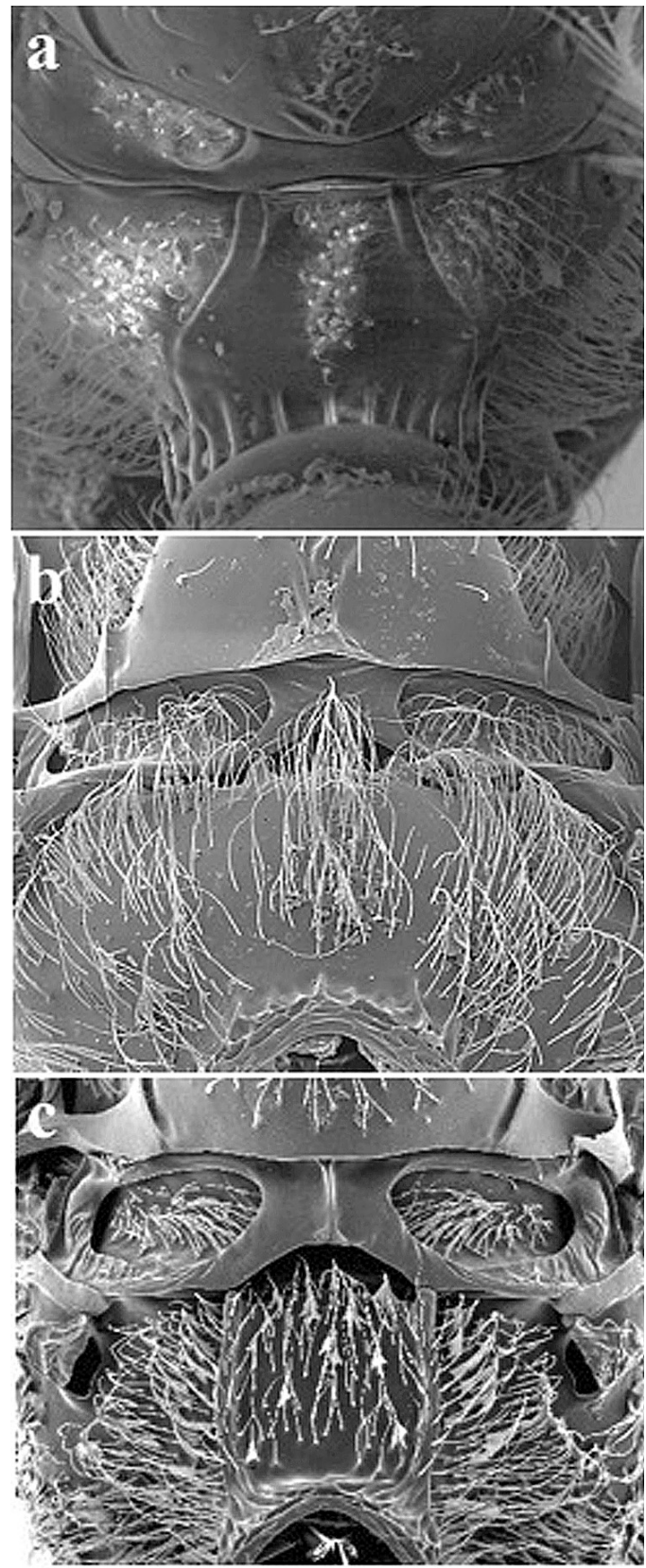

Fig. 6. Types of propodeum. - a. Alloxysta arcuata. - b. A. victrix. - c. Phaenoglyphis americana.

siphum prenathidis, Prenanthes purpurea, *Aphidius urticae, *Ephedrus plagiator": 1 ; "59/286, Anenská Hut, Orl. Hory, B.or., 8.VII.1959, Rhopalosiphoninus, Oxalis, *Ephedrus lacertosus, Praon volucre": 1; "60/106, Karlštejn, B.c, 23.V.1960, Macrosiphum rosae, Rosa, Aphidius rosae, Praon 
volucre": $2 \widehat{O} \&$ \& 1 ; ; “60/107, Karlštejn, B.c., 23.V.1960, Linosiphon, Galium silvaticum, *Aphidius linosiphonis, Praon volucre": 1; "60/109, Karlštejn, B.c., 23.V.1960, Macrosiphum rosae, Rosa, Aphidius rosae": 2ᄋ; "60/111, Čelákovice, B.c., 26.V.1960, Aulacorthum, Potentilla argentea, Aphidius urticae, Ephedrus plagiator": 39; "60/284, Hostýn, Hostýnské hory, M. or., 9.VI.1960, *Macrosiphum funestum, Rubus": 1q; "60/302, Praha, BZKU, B.c., 8.VI.1960, *Myzus ajugae, Ajuga reptans, Aphidius matricariae": 10'; "60/357, Stěhelčeves B. c., 17.VI.1960, Brevicoryne brassicae, Brassica napus": $31 \delta^{\Uparrow}$ \& 64; "60/357, Stěhelčeves B. c., 17.VI.1960, Brevicoryne brassicae, Brassica napus": 29; "60/36, Rajhrad, M. m., 19.V.1960, Brevicoryne brassicae, Brassica napus, *Diaeretiella rapae": $1 \hat{\jmath} \&$ 3 + ; “60/381, Dobříš, B. c., 23.VI.1960, Macrosiphum rosae, Rosa, Aphidius rosae": $1 \delta^{\lambda}$ \& 2ᄋ; "60/396, Praha, BZKU, B. c., 24.VI.1960, *Acyrthosiphon caraganae, Caragana arborescens, Aphidius ervi, *Ephedrus plagiator": 3 1 ; “60/419, Praha, BZKU, B c, 28.VI.1960, Myzus persicae, Urtica urens, Diaeretiella rapae": 40ึ \& 2ᄋ; "60/473, Blatnáenvs., B. m. 13.VII.1960, Brachycaudus, Senecio, Aphidius ervi”: 1ð̄; “60/516, Praha, BZKU, B. c., 20.VII.1960, Hyperomyzus, Sonchus oleraceus, Praon volucre": $10^{\Uparrow} \& 1$ \& "60/611, Bílý Kostel, B. bor, 9.VIII.1960, Sitobion avenae, Festuca nemoralis, Lysiphlebus confusus ": 10; "60/684, Sušice, B. m., 4.IX.1960, Myzus galeopsidis, Galeopsis ladanum": 19; "60/82, Karlštejn, B. c., 23.V.1960, Acyrthosiphon, Euphorbia cyparissias, Aphidius ervi”: 2 ; ; “60/86, Karlštejn, B. c., 23.V.1960, Aulacorthum, Sanguisorba minor, Aphidius urticae": $2 \lesssim \& 2$ \&; "60/96, Karlštejn, B. c., 23.V.1960, Macrosiphum rosae, Rosa, Aphidius rosae": 2+; "61/149, Praha, Seminářská zahrada, B. c., 4.VI.1961, *Macrosiphum gei, Geum, Aphidius urticae": 19; “61/155, Královský Chlmec, Slov. or, 5.VI.1961, Cryptomyzus, Ribes rubrum, Aphidius ribis": $3 \hat{\jmath}$ \& 3q; “61/199, Královský Chlmec, Slov. or, 5.VI.1961, Macrosiphum rosae, Rosa, Aphidius rosae": 1+; "61/284, Svätuša, Slov. or., 8.VI.1961, Macrosiphum rosae, Rosa, Aphidius rosae": 6ㅇ; "61/327, Piliš, Slov. N. Město, Slov. or., 9.VI.1961, Hyadaphis, Conium maculatum": 3; "61/605, Mikulov, Mor. m., 2.VII.1961, Macrosiphum rosae, Rosa, Praon volucre": 1 ; "61/64, Praha, Semináŕská zahrada, B. c., 13.V.1961, *Rhopalosiphum padi, Prunus padus, Ephedrus plagiator": $1 \delta^{\Uparrow} \& 2$ \&; “62/315, Štúrovo, Slov. m., 6.VI.1962, *Macrosiphum euphorbiae, Euphorbia palustris": 19; "62/469, Putimov, nr. Pelhřimov, B. m.,VIII.1962, Sitobion avenae, Avena sativa, Aphidius uzbekistanicus, Ephedrus plagiator": 1\%; "64/21, Karlštejn, B. c., 25.V.1964, *Aphidius linosiphonis, Linosiphon, Galium silvaticum": 1ठ̂; "65/1148, Těchobuz, nr. Pacov, B.m., 25.IX.1965, Aphis fabae, Cavariella, Compositae": 1ठ1; "66/9, Kroměříž, M.c., 19.IV.1966, Myzus persicae, Asparagus sprengeri, Aphidius matricariae ": 19; "67/14, Kláštorisko, Slov. Ráj, Slov.bor., 27.V.1967, *Macrosiphum oredonensis, Lonicera nigra": 1ㅇ; "67/17, Mnichov, B. occ., 14.VI.1967, *Macrosiphum melampyri, Melampyrum pratense”: 1 đ\& \& 19; “69/216, Praha, Seminářská zahrada, B.c., 20.VII.1969, Periphyllus, Acer platanoides, *Euaphidius setiger”: $2{ }^{\top}$; “69/220, Praha, Strahovská zahrada, B. c., 20.VII.1969, Periphyllus, Acer platanoides, Euaphidius setiger": 10;; “70/110, Rusava, Hostýnské vrchy, M. or., 17.VI.1970, Cavariella, Salix": 10̄; "70/188, V. Tatry, Tomanova dolina, Slov.bor., 23.VII.1970, *Brachycaudus klugkisti, Silene rubra": 19; "70/32, Valtice, M. m., 27.V.1970, *Periphyllus lyropictus, Acer platanoides, Euaphidius setiger, *Areopraon silvestre": 10̄; "71/158, Praha, Podolí, B. c., 18.VII.1971, Macrosiphoniella, Achillea millefolium": 1; “71/35, Praha, Kinského sady, B. c., 27.V.1971, Cryptomyzus, Ribes, Aphidius ribis, *Toxares deltiger”: 1q; “72/151, Blatnice, nr. Mladá Vožice B m, 2.VII.1972, Sitobion, Secale arvense, Aphidius uzbekistanicus": 20⿱; "74/107, Praha, BZKU,B., c., 4.VI.1974, Capitophorus, Elaeagnus angustifolia, Aphidius matricariae": 10̄; "74/110, Praha, Kinského sady, B.c, 6.VI.1974, Euceraphis punctipennis, Betula, *Betuloxys compressicornis": 1ठ̋'; “74/122, Praha, Seminářská zahrada, B.c., 7.VI.1974, Betulaphis, Betula, *Aphidius aquilus": $3 \hat{0}$ \& 2.; "78/174, Praha, Seminářská zahrada, B.c., 20.VI.1978, Cavariella, Umbelliferae, Aphidius 
salicis": 2へ \& 2ᄋ; "78/180, Praha, Dejvice, Šárka, B.c., 27.VI.1978, Macrosiphum, Rubus, Aphidius urticae": 1ठ; "81/29, Praha-Motol, B.c., 13.VII.1981, Macrosiphum rosae, Rosa, Aphidius rosae": 4; " 87/112, Holašovice, B.m., 23.VII.1987, Rhopalosiphum nymphaeae, Schizaphis, Typha angustifolia, *Praon necans": 1; "89/160, Prachatice, B.m., 22.VI.1989, Cryptosiphum, Artemisia vulgaris, *Aphidius arvensis, Ephedrus nacheri”: 19. "89/165, Nové Hrady, B.m., 23.VI.1989, Brevicoryne brassicae, Brassica napus, Diaeretiella rapae": $2 \hat{\jmath} \& 3$ 웅 "89/176, České Budějovice, B.m., 28.VI.1989, Microlophium carnosum, Urtica dioica, *Aphidius microlophiii, Aphidius urticae, *Praon yomenae": 19; "60/107, Karštejn, B.c., 27.V.1960, Linosiphon, Galium silvaticum": 1 ; "60/431, Žel.Brod, Jizerské hory, B.bor., 1.VII.1960, Nasonovia, Uroleucon, Hieracium": 19; "60/70, Srbsko, B.c., 23.V.1960, Cryptomyzus ribis, Ribes rubrum, Aphidius ribis": 1 ㅇ․

Distribution. Cosmopolitan (Ferrer-Suay et al. 2012a). New records for the Czech and Slovak Republics.

\subsection{Phaenoglyphis evenhuisi \\ Pujade-Villar \& Paretas-Martínez, 2006}

Diagnosis. Phaenoglyphis evenhuisi is mainly characterized by having radial cell closed and 3.0 times as long as wide, notauli evanescent, scutellar foveae present with a complete transverse, inner, posterior carina defined and separated by a carina, female antennae with rhinaria and antennal club beginning in F4, F1 longer than pedicel and F2, F2 subequal to F3 and F3 shorter than F4 (Fig. 2a). It is similar to Phaenoglyphis pubicollis (Thomson, 1877) but can be differentiated by the beginning of rhinaria: F4 in $P$. evenhuisi (Fig. 2a) but F1 in P. pubicollis; shape of notauli: only evanescent in $P$. evenhuisi while only evanescent in front and well-marked in back in P. pubicollis.

Material studied. 2ᄋ. "60/537, Karlík, B. c., 26.VII.1960, Brachycaudus? lychnidis, Silene alba, *Diaeretiella rapae, *Praon volucre": 19,"60/539, Karlík, B. c., 26.VII.1960, Brachycaudus, Arctium lappa": 19.19 in UB.

Distribution. Palaearctic (Ferrer-Suay et al. 2012a). New record for the Czech Republic.

\subsection{Phaenoglyphis heterocera (Hartig, 1841)}

Diagnosis. Phaenoglyphis heterocera is mainly characterized by having F1 shorter than pedicel in female (Fig. 2b) but longer in male, rhinaria and antennal club begin in F3, rounded scutellar foveae not delimited on top and bottom. It is similar to Phaenoglyphis stenos Andrews, 1978, but can be differentiated by the beginning of rhinaria: in F3 in $P$. heterocera but F2 in P. stenos; F1 shorter than pedicel in $P$. heterocera female (Fig. 2b) but F1 longer than pedicel in $P$. stenos female; F1-F3 subequal in length in $P$. heterocera female while F1-F3 not subequal in $P$. stenos female being F1 longer than F2 and F2 subequal to F3; scutellar fovea separated by a carina in $P$. heterocera but scutellar foveae partly fused in $P$. stenos.

Material studied. 20 \& 49. " $58 / 188$, Čáslavokolí, B. or., 9.VII.1958, *Uroleucon cichorii, Crepis biennis, *Lipolexis gracilis": 10 ; "60/573, Č. Brod, B. c., 28.VII.1960, Brachycaudus, Arctium lappa, *Lysiphlebus gr. fabarum": 1ठ̋; "81/35, Obrátice, B.m., 18.IX. 1981, Aphis fabae, Cirsium arvense, *Lysiphlebus fabarum": 39; "84/33, České Budějovice, B.m., 20.VI.1984, *Aphis sambuci, Sambucus nigra, ${ }^{*}$ Binodoxys angelicae, ${ }^{*}$ Praon abjectum": 1 + $.1 \delta \& 1$ in UB.

Distribution. Palaearctic (Ferrer-Suay et al. 2012a). New record for the Czech Republic.

\subsection{Phaenoglyphis longicornis (Hartig, 1840)}

Diagnosis. Phaenoglyphis longicornis is mainly characterized by having a closed radial cell 2.7 times as long as wide, pronotal and propodeal carinae, notauli present, oval scutellar foveae with straight margins, separated by a carina and not delimited at the bottom, female antennae with the beginning of rhinaria in F1, F1 longer than pedicel and F2, F2 subequal to F3 and F3 shorter than F4 (Fig. 2c). It is similar to Phaenoglyphis stricta (Thomson, 1877) but can be differentiated by the beginning of rhinaria: they are in the entire surface of F1 in P. longicornis (Fig. 2c) while they begin in the last three quarters of $\mathrm{F} 1$ in $P$. stricta (Fig. 2f); shape of scutellar foveae: not delimited on the bottom in $P$. longicornis while they are not delimited on the top and on the bottom in 
P. stricta; size of radial cell: 2.7 times as long as wide in P. longicornis but 2.4 times as long as wide in P. stricta.

Material studied. 1․ "72/153, Praha, Suchdol, B. c., 7.VII.1972, Uroleucon, Cirsium arvense, *Aphidius funebris": 1 \%

Distribution. Palaearctic (Ferrer-Suay et al. 2012a). New record for the Czech Republic.

\subsection{Phaenoglyphis ruficornis (Förster, 1869)}

Diagnosis. Phaenoglyphis ruficornis is mainly characterized by having notauli present, with a few wrinkles on the distal side of the notauli, scutellar foveae present and horizontally elongated, separated by a carina and completely open at the bottom, rhinaria and antennal club begin in $\mathrm{F} 1, \mathrm{~F} 1$ longer than pedicel and F2, F2-F4 subequal in length (Fig. 2d). It is similar to $P$. pubicollis and $P$. evenhuisi in sculpturing. However, they can be differentiated by $P$. ruficornis having the mesoscutum mostly smooth, with a few wrinkles on the distal side of the notauli, while $P$. pubicollis and $P$. evenhuisi have distinctive imbricate sculpturing on all surfaces.

Material studied. 1․ "74/214, Stankovany, Choč.pohorie, Slov.bor., 24.VI.1974, Cinara juniperi, Juniperus, *Pauesiajuniperorum": 1 .

Distribution. Holarctic (Ferrer-Suay et al. 2012a). New record for the Slovak Republic.

\subsection{Phaenoglyphis salicis (Cameron, 1883)}

Diagnosis. Phaenoglyphis salicis is mainly characterized by having a closed radial cell 2.5 times as long as wide, pronotal and propodeal carinae present, notauli weakly present, oval scutellar foveae present, completely defined and with two lines on top, female antennae with the beginning of rhinaria in F3, F1 longer than pedicel and F2, F2 shorter than F3, F3 subequal to F4 (Fig. 2e). It is similar to Phaeonoglyphis gutierrezi Andrews, 1978 , but can be differentiated by the relations among flagellomeres: F2 shorter than F3, F3-F4 subequal in length in P. salicis (Fig. 2e) while F2-F4 subequal in length in $P$. gutierrezi; shape of scutellar foveae: scutellar foveae completely defined and with two lines at the top in P. salicis but scutellar foveae slightly open at the bottom in P. gutierrezi.
Material studied. 129. "60/389, Praha, BZKU, B. c., 24.VI.1960, Cavariella, Daucus carota, *Aphidius salicis, *Binodoxys brevicornis": 5q; "68/342, Těchobuz, B. m., 25.VII.1968, *Aphis fabae, Cirsium arvense, *Lysiphlebus fabarum": 7 ․ 39 in UB.

Distribution. Palaearctic (Ferrer-Suay et al. 2012a). New record for the Czech Republic.

\subsection{Phaenoglyphis stricta (Thomson, 1877)}

Diagnosis. Phaenoglyphis stricta is mainly characterized by having notauli, scutellar fovea with straight sides and open on the top and on the bottom; female antennae with rhinaria and antennal club beginning in the last two thirds of F1, F1 longer than pedicel and F2, F2-F4 subequal in length (Fig. 2f). It is similar to Phaenoglyphis insperatus Belizin, 1973, but can be differentiated by the shape of scutellar foveae: they are with straight sides and open both on the top and on the bottom in P. stricta while rounded and slightly open at the bottom in $P$. insperatus; size of radial cell: 2.4 times as long as wide in $P$. stricta but in $P$. insperatus 2.9 times as long as wide.

Material studied. 4ㅇ. “60/342, Raná, Louny, B.c., 17.VI.1960, *Aphis urticata, Urtica dioica, *Binodoxys acalephae": 4 + 1 i in UB.

Distribution. Palaearctic and Neotropical Regions (Ferrer-Suay et al. 2012a). New record for the Czech Republic.

\subsection{Phaenoglyphis villosa (Hartig, 1841)}

Diagnosis. Phaenoglyphis villosa is characterized by having a partially open radial cell 2.1-2.7 times as long as wide, pronotal and propodeal carinae present, notauli absent, scutellum with two deep oval foveae more or less separated by a carina or completely fused, female antennae with the beginning of rhinaria in F3, F1 as long as pedicel or slightly longer, F1 subequal to F2, F2 shorter than F3, F3 shorter than F4, male antennae with the beginning of rhinaria in F3, F1 subequal to F2, F2 shorter than F3. At the moment $P$. villosa is easily differentiated from the other Phaenoglyphis species because it is the only one with a partially open radial cell.

Material studied. 43त \& 54ㅇ. "58/154, Praha, Kinského sady, B.c., 2.VII.1958, Aphis 
Spirea, *Binodoxys angelicae, Ephedrus plagiator": 1ठ̂;; "58/181, Opatov, nr. Svitavy, B. or. 8.VII.1958, Aphis fabae, Beta vulgaris, *Binodoxys acalephae": $10^{\pi}$ \& 1; "59/20, Kysak, Slov. or., 23.V.1959, Aphis fabae, Euonymus europaeus, Ephedrus plagiator": 4ㅇ; "59/20, Kysak, Slov. or., 23.V.1959, Aphis fabae, Euonymus europaeus, Ephedrus plagiator": 10; "59/26, Praha, BZKU, B.c., 14.V.1959, Aphis fabae, Euonymus europaeus, Ephedrus plagiator, *Praon abjectum": 19; "59/26, Kapušany, S. or., 14.V.1959, Aphis fabae, Euonymus europaeus, Binodoxys angelicae, Praon abjectum": 1ठ; "59/29, Kapušany, S. or., 14.V.1959, Aphis fabae, Euonymus europaeus, Praon abjectum": 3q; "60/337, Praha, BZKU, 15.VI.1960, Myzus cerasi, Prunus cerasus, Ephedrus persicae": 19 ; “60/341, Raná, Louny, B.c., 17.VI.1960, Brevicoryne brassicae, Sinapis arvenses, Diaeretiella rapae”: 1今̄; “60/357, Stěhelčeves B. c., 17.VI.1960, Brevicoryne brassicae, Brassica napus": 1 đิ \& 1; "60/364, Praha, Seminářská zahrada, B. c., 21.VI.1960, Liosomaphis berberidis, Berberidis vulgaris": 19; "60/404, Praha, BZKU, B. c., 25.VI.1960, Trifolium fragiferum": 19; "60/405, Praha, BZKU, B. c., 25.VI.1960, Aphis farinosa, Salix repens rosmarinifolia, Binodoxys angelicae, *Lysiphlebus cardui": $3 \hat{\jmath} \& 4$ 4; “60/419, Praha, BZKU, B. c., 28.VI.1960, Myzus persicae, Urtica urens, Diaretiella rapae": $2 \hat{0}$ \& 2 ; "60/423, Praha, BZKU, B. c., 28.VI.1960, Aphis fabae, Cirsium, Lysiphlebus fabarum": 10; "60/460, Mažice, B. m., 12.VII.1960, *Aphis craccae, Vicia cracca, *Lysiphlebus fritzmuelleri”: 1ठ& 6ㅇ; “60/463, Mažice, B. m., 12.VII.1960, Schizaphis, Typha angustifolia, Diaeretiella rapae, *Aphidius urticae": $8 \uparrow \&$ 2ð; " 60/515, Praha, BZKU, B. c., 20.VII.1960, Myzus persicae, Beta vulgaris": 2ð⿱; "60/516, Praha, BZKU, B. c., 20.VII.1960, Hyperomyzus, Sonchus oleraceus, Praon volucre": 10̄; "60/517, Praha, BZKU, B. c., 20.VII.1960, Aphis urticata, Urtica urens, Diaeretiella rapae": 2 ; “60/543, Trněný Újezd, B. c., 26.VII.1960, Aphis fabae, Beta vulgaris, Lysiphlebus fabarum 10; “60/543, Trněný Újezd, B. c., 26.VII.1960, Aphis fabae, Beta vulgaris, Lysiphlebus fabarum”: 1 ; "60/59, Korno, B. c., 23.V.1960, Hydaphis,
Galium mollugo, *Aphidius matricariae": 1ð̄; "60/607, Těchobuz, nr.Pacov, B. m., Aphis craccae, Vicia cracca, Lysiphlebus fritzmuelleri”: 2ð’; “60/667, Praha-Košíře, B.c.,24.VIII.1960, Aphis fabae, Beta vulgaris": 13̂; "61/218, Královský Chlumec, Slov. or, 6.VI.1961, Myzus ligustri, Ligustrum, *Monoctonus ligustri, Praon volucre": 1; "61/245, Somotor, Slov.m., 7.VI.1961, Aphis fabae, Silene alba, Lysiphlebus fabarum": 20 \& 2.; "62/396, Františkov, nr. M. Vožice, B. m., VIII.1962, Solanum": 10̄; "62/528, Smilovy hory, B. m., VIII.1962, Aphis fabae, Cirsium, Lysiphlebus fabarum": $10^{\Uparrow}$ \& 2ᄋ; “66/197, Lednice, M. m., 14.VII.1966, Hyalopterus, Phragmites communis, *Aphidius transcaspicus": 10ึ; “70/116, Valtice, M. m., 19.VI.1970, *Aphis urticata, Urtica dioica, Lysiphlebus fabarum": 1 ; ; "70/209, Jičín, B. bor., 20.VIII.1970, Aphis fabae, Yucca, Lysiphlebus fabarum": 19; "73/360, Těchobuz, B. m., 2.IX.1973, Impatientinum balsamines, Impatiens nollitangere ": $2 \curvearrowright \& 2 \bigcirc ;$; $74 / 108$, Praha, BZKU, B.c., 4.VI.1974, Aphis fabae, Evonymus europaeus, Praon abjectum": 10 \& 2ᄋ; "74/331, Praha, BZKU, B.c., 24.VII.1974, *Rhopalosiphum nymhaeae, Sagittaria": 10َ; "74/349, Praha, BZKU, B.c., 9.VIII.1974, Rhopalosiphum nymheae, Sagittaria, *Praon necans": 1ठิ; "81/35, Obrátice, B.m,., 18.IX.1981, Uroleucon, Aphis fabae, Cirsium arvense, Lysiphlebus fabarum": 19; "83/10, České Budějovice, B.m., 7.VI.1983, Liosomaphis berberidis, Berberis, Aphidius hortensis": 2へ \& 1; "84/134, Pacov, B.m., 4.VIII.1984, Aphis fabae, Cirsium arvense, Binodoxys acalephae": 19; "84/141, Jetřichovec, B.m., 6.VIII.1984, Aphis fabae, Cirsium arvense, Lysiphlebus cardui": $4 \bigcirc$ त \& 2 + "84/145, Pacov, B.m., 8.VIII.1984, Aphis fabae, Cirsium arvense": 2今̄; "84/149, Pelhřimov, B.m., 8.VIII.1984, Undet. (green aphids), Polygonum": 19; "85/3, České Budějovice, B.m., 17.VI.1985, Aphis craccae, Vicia cracca, Binodoxys acalephae, Praon abjectum": 1; "87/112, Holašovice, B.m., 23.VII.1987, Rhopalosiphum nymphaeae, Schizaphis, Typha angustifolia, Praon necans": 1ठ; "61/287, Svätoša, S.or., 8.VI.1961, Aphis fabae, Chenopodium": $10 \hat{\jmath} .50$ \& 5 in UB. 
Table 2. List of the new records per country of each Charipinae species identified in this work.

The Check and Slovak Republics

Alloxysta arcuata

Alloxysta brevis

Alloxysta castanea

Alloxysta citripes

Alloxysta consobrina

Alloxysta macrophadna

Alloxysta mullensis

Alloxysta obscurata

Alloxysta pilipennis

Alloxysta pleuralis

Alloxysta pusilla

Alloxysta victrix

Phaenoglyphis villosa
The Check Republic

Alloxysta basimacula

Alloxysta brachyptera

Alloxysta circumscripta

Alloxysta hendrickxi

Alloxysta kovilovica

Alloxysta leunisii

Alloxysta melanogaster

Alloxysta nigricans

Alloxysta pallidicornis

Alloxysta pilosa

Alloxysta postica

Alloxysta ramulifera

Alloxysta sawoniewiczi

Alloxysta semiaperta

Phaenoglyphis evenhuisi

Phaenoglyphis heterocera

Phaenoglyphis longicornis

Phaenoglyphis salicis

Phaenoglyphis stricta

Phaenoglyphis xanthochroa
The Slovak Republic

Alloxysta fracticornis

Phaenoglyphis ruficornis

Slovenia

Alloxysta halterata

Poland

Alloxysta macrophadna

Alloxysta pallidicornis
Distribution. Cosmopolitan (Ferrer-Suay et al. 2012a). New records for the Czech and Slovak Republics.

\subsection{Phaenoglyphis xanthochroa Förster, 1869}

Diagnosis. Phaenoglyphis xanthochroa is easily differentiated from the other Phaenoglyphis species because of its dark yellow body and its deeply excavated notauli. It is similar to Phaenoglyphis pilosus Andrews, 1978, but they can be differentiated by the relations among F2F10: F2 shorter than F3, F3-F10 subequal in length and width in P. xanthochroa but F2-F10 subequal in length and width in P. pilosus; mesoscutum and scutellum with few scattered setae in $P$. xanthochroa while mesoscutum and scutellum completely covered by long setae in P. pilosus.

Material studied. 60^."78/214, Chvalčov, M. or., 14.VII.1978, *Impatientinum balsamines, Impatiens nolitangere, *Monoctonus nervosus": $6 \widehat{\partial} .10$ in UB.

Distribution. Palaearctic (Ferrer-Suay et al. 2012a). New record for the Czech Republic.

\section{Discussion}

Numerous host relations have been established here (Table 1). In total 389 new trophic relations are documented in this work. The number in parentheses after each species is the number of new host records for that species: Alloxysta arcuata (51), A. basimacula (1), A. brachyptera (2), A. brevis (44), A. castanea (28), A. citripes (2), A. circumscripta (19), A. consobrina (14), A. fracticornis (1), A. halterata (1), A. hendrickxi (2), A. kovilovica (1), A. leunisii (1), A. macrophadna (12), A. melanogaster (5), A. mullensis (14), A. nigricans (1), A. obscurata (3), A. pallidicornis (3), A. pilipennis (32), A. pilosa (1), A. pleuralis (27), A. postica (3), A. pusilla (22), A. ramulifera (7), A. sawoniewiczi (2), A. semiaperta (8), A. victrix (45), Phaenoglyphis evenhuisi (2), P. heterocera (5), P. longicornis (1), P. ruficornis (1), $P$. salicis (3), P. stricta (1), P. villosa (23) and $P$. xanthochroa (1).

The material studied was collected mainly in former Czechoslovakia. Nearly all the species listed and localities are new for the Czech and Slovak Republics. Table 2 shows the species cited for the first time in each of the countries studied in this work. All the Charipinae species here identi- 
fied, except $A$. postica, are recorded for the first time in this area. Up to now, only one recent study has focused on the Charipinae species present in Europe, from the Balkan Peninsula (Ferrer-Suay et al. 2013f). In that study, nine species were recorded for the first time from that region: Alloxysta arcuata, A. brevis, A. castanea, A. fracticornis, A. fuscicornis (Hartig, 1841), A. macrophadna, A. mullensis, A. pleuralis, and A. salicicola; and two new species were described: Alloxysta kovilovica Ferrer-Suay \& Pujade-Villar, 2013 and $A$. slovenica Ferrer-Suay \& Pujade-Villar, 2013. Vasileva-Sumnalieva (1976) already recorded five Charipinae species from the Balkan Peninsula (Alloxysta macrophadna, A. nigrita (Thomson, 1862), A. postica, Apocharips trapezoidea (Hartig, 1841) and Phaenoglyphis villosa). However, these records must be confirmed taking into account the taxonomic chaos within this subfamily before our revisions. Additionally, with the same considerations, A. postica was cited from the Czech Republic by Dalla-Torre \& Kieffer (1910).

The need to continue the sampling and studies of the Charipinae fauna all around the world must be emphasized, as it is important to collect more material to know the real distribution patterns of the Charipinae species, which are nowadays mostly just spots on the globe.

The information provided in this study is very valuable for the study of host specialization and prefererences of Charipinae. The information related to the Charipinae hosts is still very sparse and the study of old collections with a complete register of their hosts is one of the bases of this knowledge. Reviews of the aphidiine parasitoids and their aphid-plant associations are presented in Starý (2006) and Starý and Lukáš (2009).

Acknowledgments. We would like to thank James Carpenter (American Museum of Natural History, New York, USA) for his kind revision and valuable suggestions. This research was supported by the project CGL2011-22889 of the "Ministerio de Ciencia e Innovación" (Spain) and the grant AP2009-4833 of the "Ministerio de Educación" (Spain). The research by P. Starý was conducted with institutional support RVO: 60077344. Our thanks are also expressed to J. Stará and L. Smetanová (Lab. Aphidol., Inst. Entomol. ASCR) for valuable long-term assistance in the field and laboratory.

\section{References}

Benoit, P. L. G. 1956: Deux Cynipidae-Charipinae inedits du Congo Belge. - Revue de zoologie et de botanique africaines 53: 437-440.

Cameron, P. 1879: On some new or little known British Hymenoptera. - Transactions of the Entomological Society of London 1879: 107-119.

Cameron, P. 1883: Descriptions of sixteen new species of parasitic Cynipidae, chiefly from Scotland. - Transactions of the Entomological Society of London 16(4): 365-374.

Cameron, P. 1886: The fauna of Scotland, with special referenctasche to Clydesdale and the western district. Proccedings of the Natural History Society of Glasgow 3: 53-95.

Curtis, J. 1838: British entomology; being illustrations and descriptions of the genera of insects found in Great Britain and Ireland: containig coloured figures from nature of the most rare and beautiful species, and in many instances of the plants upon which they are found. - Privately published, London. Vol. 15, plates 674-721.

Dalla Torre, K. W. \& Kieffer, J. J. 1910: Das Tierreich XXIV: Cynipidae. - R. Friedlander \& Sons, Berlin. 24: 1-891.

Fergusson, N. D. M. 1986: Charipidae, Ibaliidae and Figitidae (Hymenoptera: Cynipoidea). - Handbook of Identification of British Insects 8(1c): 1-55.

Ferrer-Suay, M., Paretas-Martínez, J., Selfa, J. \& PujadeVillar, J. 2012a: Taxonomic and synonymic world catalogue of the Charipinae and notes about this subfamily (Hymenoptera: Cynipoidea: Figitidae). - Zootaxa 3376: 1-92.

Ferrer-Suay, M., Selfa, J. \& Pujade-Villar, J. 2012b: Revision of V.I. Belizin's type material of Alloxysta (Hymenoptera: Figitidae: Charipinae) deposited in the Zoological Institute of the Russian Academy of Sciences. - Zoosystematica Rossica 21(2): 279-290.

Ferrer-Suay, M., Selfa, J. \& Pujade-Villar, J. 2012c: Revision of the type material of Ionescu collection related to Charipinae subfamily (Hymenoptera: Figitidae) deposited in the "Grigore Antipa" National Museum of Natural History (Bucharest). - Travaux du Museum d'Histoire Naturelle "Grigore Antipa" 55(2): 277 284.

Ferrer-Suay, M., Selfa, J. \& Pujade-Villar, J. 2013a: Revision of Thomson and Zetterstedt collections of Alloxysta genus deposited in Lund Museum of Zoology (Sweden). - Entomologisk Tidskrift 134: 77-102.

Ferrer-Suay, M., Selfa, J. \& Pujade-Villar, J. 2013b: Revision of Curtis collection of Alloxysta (Hymenoptera: Figitidae: Charipinae) deposited in National Museum of Victoria (Australia). - Memoirs of Museum Victoria 70: 11-16.

Ferrer-Suay, M., Selfa, J. \& Pujade-Villar, J. 2013c: The Alloxysta type material (Hym., Figitidae: Charipinae) in the National Museum of Natural History, Washington, DC and the Canadian National Collection of In- 
sects, Ottawa. - The Canadian Entomologist 145(6): 603-625.

Ferrer-Suay, M., Selfa, J., Notton, D. \& Pujade-Villar, J. 2013d: Revision of the types of species of Alloxysta Förster, 1869 described by Cameron and Fergusson (Hymenoptera: Figitidae: Charipinae) deposited in the Natural History Museum (London) including a key to Alloxysta species of the Great Britain fauna. - European Journal of Taxonomy 53: 1-27.

Ferrer-Suay, M., Selfa, J. \& Pujade-Villar, J. 2013e: Charipinae fauna (Hymenoptera: Figitidae) from Asia, with description of eleven new species. - Zoological studies 52: 41.

Ferrer-Suay, M., Selfa, J., Tomanović, Z., Janković, M., Kos, K., Rakhshani, E. \& Pujade-Villar, J. 2013f: Revision of Alloxysta from the north-western Balkan Peninsula with description of two new species (Hymenoptera: Figitidae: Charipinae). - Acta Entomologica Musei Nationalis Pragae 53(1): 347-368.

Ferrer-Suay, M., Janković, M., Selfa, J., Van Veen, F., Tomanović, Z., Kos, K., Rakhshani, E. \& Pujade-Villar, J. 2014: Qualitative analysis of aphid and primary parasitoid trophic relations of genus Alloxysta (Hymenoptera: Cynipoidea: Figitidae: Charipinae). — Environmental Entomology 43(6): 1485-1495.

Förster, A. 1869: Ueber die Gallwespen. — Verhandlungen der Zoologisch-Botanischen Gesellschaft in Wien 19: 327-370.

Hartig, T. 1840: Ueber die Familie der Gallwespen. Zeitschrift für Entomologie (Germar) 2: 176-210.

Hartig, T. 1841: Erster nachtrag zur naturgeschichte der Gallwespen. — Zeitschrift für Entomologie (Germar) 3: 322-358.

Hellén, W. 1963: Die Alloxystininen Finnlands (Hymenoptera: Cynipidae). - Fauna Fennica 15: 1-23.

Kieffer, J. J. 1902: Description de quelques Cynipides nouveaus ou peu connus et de deux de leurs parasites (Hymenopteres). - Bulletin de la Société d'Histoire Naturelle de Metz 10: 1-18.

Kierych, E. 1988: A new genus and a new species of cyni- poids (Hymenoptera, Cynipoidea, Charipidae) from Poland. - Annales Zoologici 41: 351-354.

Menke, A. S. \& Evenhuis, H. H. 1991: North American Charipidae: key to genera, nomenclature, species checklists, and a new species of Dilyta Förster (Hymenoptera: Cynipoidea). — Proceedings of the Entomological Society of Washington 93: 136-158.

Paretas-Martínez, J., Arnedo, M. A., Melika, G., Selfa, J., Seco-Fernández, M. V., Fülöp, D. \& Pujade-Villar, J. 2007: Phylogeny of the parasitic wasp subfamily Charipinae (Hymenoptera, Cynipoidea, Figitidae). Zoologica Scripta 36: 153-172.

Pujade-Villar, J. \& Paretas-Martínez, J. 2006: Phaenoglyphis "versus" Hemicrisis, and the description of a new sculptured species of Charipinae (Hymenoptera: Figitidae). - European Journal of Entomology 103: 477-481.

Starý, P. 2006: Aphid parasitoids of the Czech Republic (Hymenoptera: Braconidae, Aphidiinae). - Academia Publ. House, Praha. 430 pp.

Starý, P. \& Lukáš, J. 2009: Aphid parasitoids and their tritrophic associations in Slovakia (Hymenoptera: Braconidae, Aphidiinae). - Acta Hymenopterologica Slovaka 1: 1-63.

Thomson, C. G. 1862: Försök till uppställning och beskrifning af Sveriges Figiter. - Öfversigt af Kongliga Svenska Vetenskaps-akademiens förhandlingar 18: 395-420.

Thomson, C. G. 1877: Öfversikt af Sveriges Cynips-arter. - Opuscula Entomologica 8: 778-820.

Vasileva-Sumnalieva, L. 1976: On the fauna and biology of the subfamily Charipinae (Hymenoptera, Cynipidae) in Bulgaria. - Acta Zoologica Bulgarica 5: 22 26.

Westwood, J. O. 1833: Notice of the habits of a Cynipidous insect parasitic upon the Aphis rosae with descriptions of several other parasitic Hymenoptera. - Magazine of Natural History 6: 491-497.

Zetterstedt, J. W. 1838: Insecta Lapponica descripta: Hymenoptera. Voss, Lipsiae. pp. 315-476. 